da Costa R. Tavares (Orcid ID: 0000-0002-9621-6281)

Zanardo Stefano (Orcid ID: 0000-0002-0847-1427)

Bagli Stefano (Orcid ID: 0000-0002-1194-6665)

Hilberts A. G. J. (Orcid ID: 0000-0003-2329-6724)

Samela Caterina (Orcid ID: 0000-0003-3364-4083)

Castellarin Attilio (Orcid ID: 0000-0002-6111-0612)

\title{
Predictive modelling of envelope flood extents using geomorphic and climatic- hydrologic catchment characteristics
}

\section{R. Tavares da Costa ${ }^{1,2}$, S. Zanardo ${ }^{3}$, S. Bagli ${ }^{1}$, A. G. J. Hilberts ${ }^{3}$, S. Manfreda ${ }^{4}$, C.} Samela ${ }^{2}$, and A. Castellarin ${ }^{2}$

${ }^{1}$ GECOsistema Srl, Viale Giosuè Carducci, 15, 47521, Cesena, Italy.

2 DICAM, University of Bologna, School of Engineering, Viale del Risorgimento, 2, 40136, Bologna, Italy.

${ }^{3}$ Risk Management Solutions Ltd., 30-36 Monument St, London EC3R 8NB, UK.

${ }^{4}$ DICEA, University of Naples Federico II, 80125 Naples, Italy.

Corresponding author: Ricardo Tavares da Costa (ricardotavarescosta@gmail.com)

\section{Key Points:}

- Flood descriptors are used to promptly map flood-prone areas, but strongly depend on benchmarks and the transferability assumption.

- Relationships between a flood descriptor and catchment characteristics are established to relax the benchmark and transferability problem.

- A random forest regression is effectively used for predictive modelling of envelope flood extents on a large scale.

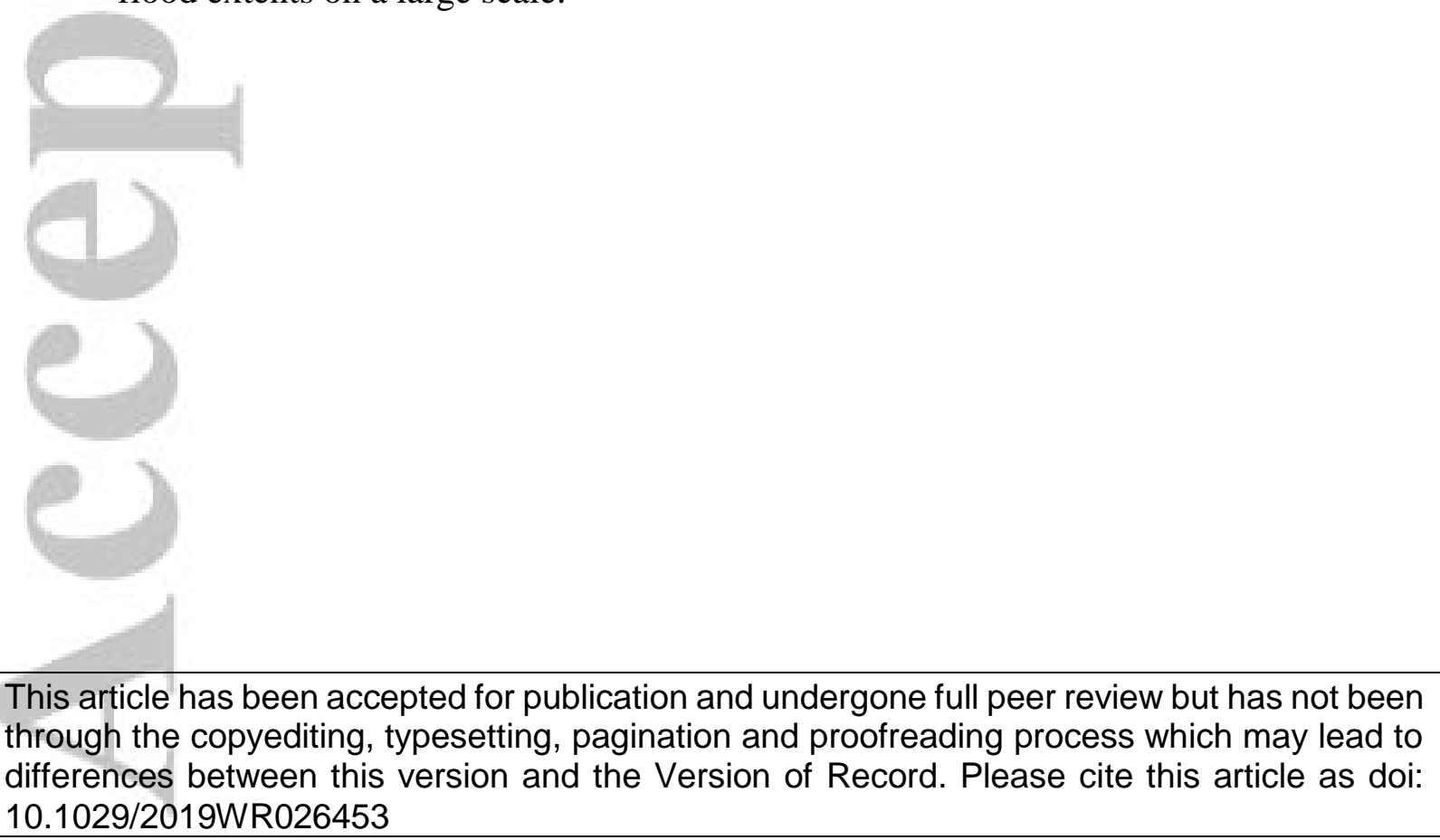




\section{Abstract}

A topographic index (flood descriptor) that combines the scaling of bankfull depth with morphology was shown to describe the tendency of an area to be flooded. However, this approach depends on the quality and availability of flood maps and assumes that outcomes can be directly extrapolated and downscaled. This work attempts to relax these problems and answer two questions: 1) Can functional relationships be established between a flood descriptor and geomorphic and climatic-hydrologic catchment characteristics? 2) If so, can they be used for low-complexity predictive modelling of envelope flood extents? Linear stepwise and random forest regressions are developed based on classification outcomes of a flood descriptor, using high-resolution flood modelling results as training benchmarks, and on catchment characteristics. Elementary catchments of four river basins in Europe (Thames, Weser, Rhine and Danube) serve as training dataset, while those of the Rhône river basin in Europe serve as testing dataset. Two return periods are considered, the 10- and 10,000-year. Prediction of envelope flood extents and flood-prone areas show that both models achieve high hit rates with respect to testing benchmarks. Average values were found to be above $60 \%$ and $80 \%$ for the 10 - and the 10,000-year return periods, respectively. In spite of a moderate to high false discovery rate, the critical success index value was also found to be moderate to high. It is shown that by relating classification outcomes to catchment characteristics the prediction of envelope flood extents may be achieved for a given region, including ungauged basins.
\end{abstract}

\title{
Plain Language Summary
}

Topographic features can be extracted from a digital terrain to identify floodplains. In turn, the classification of these features can be used to represent flood extents. The classification, however, depends on existing flood maps to be used as reference for its calibration in a small portion of the study area, before flood extents can be extrapolated. This work seeks to improve this dependence on the existence of a reference and the assumption that extrapolation can be performed without considering the physical differences between areas. To do so, a machine learning model was developed using the classification outcomes and characteristics of four river basins in Europe (Thames, Weser, Rhine and Danube) and was tested in the Rhône river basin in Europe, showing promising results. This development should help stakeholders to allocate time and money better, by giving them nearly instantaneous views of areas that can potentially be affected by floods, with an associated probability of occurrence, a physical basis for extrapolation and without needing a reference flood map for calibration for each case.

\section{Introduction}

Floods pose a serious threat to individuals and communities as shown by disaster data found, for example, in the International Disaster Database (EM-DAT) of the Centre for Research of the Epidemiology of Disasters (CRED). A United Nations report on the Human cost of weather related disasters (CRED/UNISDR, 2016) illustrates the dimension of the problem well: $47 \%$ of all disasters since 1995 have been floods, affecting a total of 2.3 billion people worldwide. This previous experience paints a grim picture and there is mounting evidence for an increase in frequency and intensity of severe floods due to climate change (Milly et al., 2002; Aerts et al., 2006; Kleinen and Petschel-Held, 2007; Alfieri et al., 2017; Barichivich et al., 2018; Sassi et al., 2019). On the other hand, the increase of socio-economic activities in flood-prone areas perseveres in a number of countries, making exposure of persons and assets, including critical infrastructure, a serious problem (de Moel et al., 2009; EEA, 2016; Kron et al., 2019). 
Thus, understanding flood risk is of great importance to the management of socioeconomic and environmental impacts. Disaster risk reduction (i.e., mitigation, preparedness, response and recovery) can greatly benefit from innovative tools, able to further inform the decision-making process. Governmental organizations use flood maps - a critical component of risk assessment - for emergency, spatial planning and awareness raising, while, in the insurance sector, flood maps are critical for managing portfolios, risk screening and assessing long-term financial solvency (de Moel et al., 2009). The vital importance of flood mapping is also recognized in the EU Floods Directive (2007/60/EC) that mandates member states to produce flood hazard and risk maps.

Flood mapping is traditionally available at the reach-scale and in urban settings (Horritt \& Bates, 2002), where researchers devote themselves to increasing the level of detail (i.e., physics and spatial resolution) of flood models, an example being the move towards hyper-resolution flood modelling (e.g., Noh et al., 2018). Instead, from regional to global scales, authors tend to focus more on simplification, as parsimonious models are more suitable to be used over larger domains due to their higher computationally efficiency (Yamazaki et al., 2011; Neal et al., 2012a,b; Pappenberger et al., 2012; Winsemius et al., 2013; Alfieri et al., 2014; Sampson et al., 2015; Dottori et al, 2016; Rebolho et al., 2018; Zheng et al., 2018). The level of detail in flood models and their large spatial coverage are two desirable but often competing properties; in other words, it is hard to setup a flood model with one of these characteristics without compromising the other. Adding to long simulation times, the calibration and validation of models in standard approaches to flood hazard mapping (please refer to Grimaldi et al., 2013, for more details) pose significant challenges. In global hydrological models (Bierkens, 2015), calibration is crucial to improve simulations (e.g., Hirpa et al., 2018), but requires large amounts of reliable streamflow observations that are scarcely available. In hydrodynamic models, calibration is also invaluable (e.g., Wood et al., 2016) and it is not uncommon to find numerical instabilities that need to be solved beforehand (e.g., by adjusting the time step or adding numerical diffusion). All these complexities, on top of the need for computational power and the difficulty in finding reliable validation data (e.g., Bernhofen et al., 2018) counters the effort for up-to-date flood maps at any location or any time.

Bottlenecks, such as the ones presented above, motivated a number of authors to produce alternative low-complexity solutions that rely on data-driven methods (Schumann et al., 2014a; Tang et al., 2018; Giovannettone et al., 2018; Caprario \& Finotti, 2019; Zhao et al., 2019). Some take advantage of the causality between historical floods and the floodplain hydraulic geometry (e.g., Bhowmik, 1984; McGlynn and Seibert, 2003; Dodov and FoufolaGeorgiou, 2006) and make use of digital elevation models (DEMs) that are datasets representing the Earth's surface, distributed as gridded values of local terrain elevations (Tavares da Costa et al., 2019b). For example, Nardi et al. (2006, 2013, 2019), Morrison et al. (2018) and Annis et al. (2019) employed a flat-water approach (i.e., intersection of a water level with the surrounding DEM, or a variation of it, such as the HAND - Height Above the Nearest Drainage; Rennó et al., 2008; Nobre et al., 2016) to delineate floodplains. The authors used a variable water level at each stream pixel from a stream-order averaged linear scaling relation (power law of upslope contributing area) obtained either from a generalization of outlet discharges and the Manning uniform flow equation or through calibration with reference data. Interestingly, using a measure-of-fit of the delineated floodplains, the authors found that consistent floodplain delineations can be obtained with constant values of power law coefficients (Nardi et al., 2019). Moreover, Annis et al. (2019) also found that the optimal power law exponent varied with spatial resolution of the DEM, return period and Strahler stream order. 
Degiorgis et al. (2012) proposed the delineation of flood-prone areas from a location where a flood map exists to one where it does not. This extrapolation procedure was achieved by threshold binary classification; in other words, by the identification of the isoline (the optimal threshold, $\mathrm{TH}$ ) of a chosen flood descriptor that best approximated the areal extent of an existing flood map. Flood descriptors can be defined as quantitative layers extracted from DEMs that correlate to the tendency of an area to flood.

Manfreda et al. (2014, 2015) and Samela et al. (2016) improved the method introduced by Degiorgis et al. (2012) by evaluating different flood descriptors in terms of their suitability to delineating flood-prone areas. In their studies, the Geomorphic Flood Index (GFI, Samela et al., 2017), was found to be the best performing and the most consistent hydrogeomorphic descriptor amongst the ones analysed (Manfreda et al., 2015; Samela et al., 2016, 2017), of which the HAND) was one. Building upon this, Samela et al. (2017) and Tavares da Costa et al. (2019a) successfully delineated flood-prone areas at the continental scale by dramatically reducing computational times and costs, opening new possibilities for flood risk assessment and management over large-scales. In Tavares da Costa et al. (2019a), optimal thresholds of the GFI were also shown to be positively correlated to flood extents associated with specific return periods.

In a different effort, Jafarzadegan and Merwade (2017) experimented with regression models, obtained by analysis of climate and catchment characteristics, to delineate the 100year floodplains in North Carolina, US. The delineation was performed based on a range of thresholds of the HAND model, used as the flood descriptor. The authors utilized the United States Federal Emergency Management Agency's Flood Insurance Rate Maps as benchmark for validating the results, but pointed out their uncertain and subjective nature. This approach was later extended by Jafarzadegan et al. (2018) and Jafarzadegan and Merwade (2019) to include a probabilistic description of the 100-year floodplains.

The data-driven approach described above complements traditional flood modelling, because its underlaying principle is different and because it provides a cost-effective alternative that can fully exploit big, high-resolution datasets, without limiting the scale of application nor compromising computational speed (Di Baldassare et al., 2020). Being mostly DEM-based, the approach also lessens the problem of data-scarcity often found, enabling the delineation of flood extents in any given catchment, based solely on the regression between envelope flood extents and catchment characteristics. The questions that the approach poses are: 1) Can functional relationships also be established between the GFI and catchment characteristics? 2) If so, can these relationships be used for low-complexity predictive modelling of envelope flood extents?

In this study, and differently from Jafarzadegan and Merwade (2017), a deterministic classification of the GFI, based on a specific objective function, is used to derive a $T H$ for a larger number of training elementary catchments (i.e., hydrological units defined as the "portion of basin directly drained by a river stretch, between two confluences, or from the headwater to the first confluence" in Castellarin et al. (2018); see supporting information Figure $\mathrm{S} 1$ for an illustration of this concept) of four different major river basins in Europe with significantly different characteristics and for two return periods (the 10- and 10,000year). Values of $T H$ correspond to unique envelope flood extents; in other words, the GFI layer isolines that best envelope a given benchmark flood hazard map. Consistent binary masks of high-resolution flood hazard maps are used as benchmark and were obtained from Risk Management Solutions (RMS), a recognized catastrophe risk modelling company, that applied a standard flood hazard mapping approach. 
Subsequently, regression models are established between the $T H$ - the target variable - and a set of geomorphic and climatic-hydrologic catchment characteristics - the explanatory variables - different from those in Jafarzadegan and Merwade (2017), tested beforehand in terms of multicollinearity. Regression models were objectively calibrated and optimized for the prediction of flood extents and flood-prone areas.

In this way, two major drawbacks found in previous applications are relaxed: 1) the complete dependence on benchmarks, since in this approach they are only needed to train the models and not for every location where flood-prone areas are to be delineated, as is the case in Degiorgis et al. (2012) for example; and, 2) the assumption of transferability of the TH without any physical basis, as is also the case in Degiorgis et al. (2012) for example, since here catchment geomorphic and climatic-hydrologic characteristics are used to regress the $T H$.

Finally, flood-prone areas in elementary catchments of a distinct major river basin in Europe - from those used in the regression models - are delineated using a $T H$ predicted by the regression models. Each resulting delineation is compared to the benchmark to assess the ability of the method to predict the extent of the envelope of major floods.

This paper is organized as follows: in section 2, the workflow to develop and test the predictive models of envelope flood extents is presented and each step of this workflow is described in detail; in section 3, the four river basins in Europe (Thames, Weser, Rhine and Danube), used to train the models, and the Rhône river basin in Europe, used to validate the models, are presented alongside the data sources used to obtain the physical characteristics of the river basins. Furthermore, a brief description of the workflow used to obtain the benchmark flood maps is explained; in section 4, the results obtained for each part of the methodological workflow, i.e., classification and physical characterization of elementary catchments, model development and prediction, are presented; and, in section 5, the main conclusions are drawn and future work is addressed.

\section{Development and testing of predictive models}

The methodology adopted for the development and testing of predictive models is based on the prior definition of a flood descriptor, the GFI, whose isolines are used to classify benchmark flood extents. The unique $T H$ values resulting from the classification are then related to a selection of geomorphic and climatic-hydrologic catchment characteristics by two distinct types of regression models. The establishing of such relations allows for the prediction of $T H$ based on physical inputs of any given river basin. In Figure 1, the general methodological workflow is presented. 


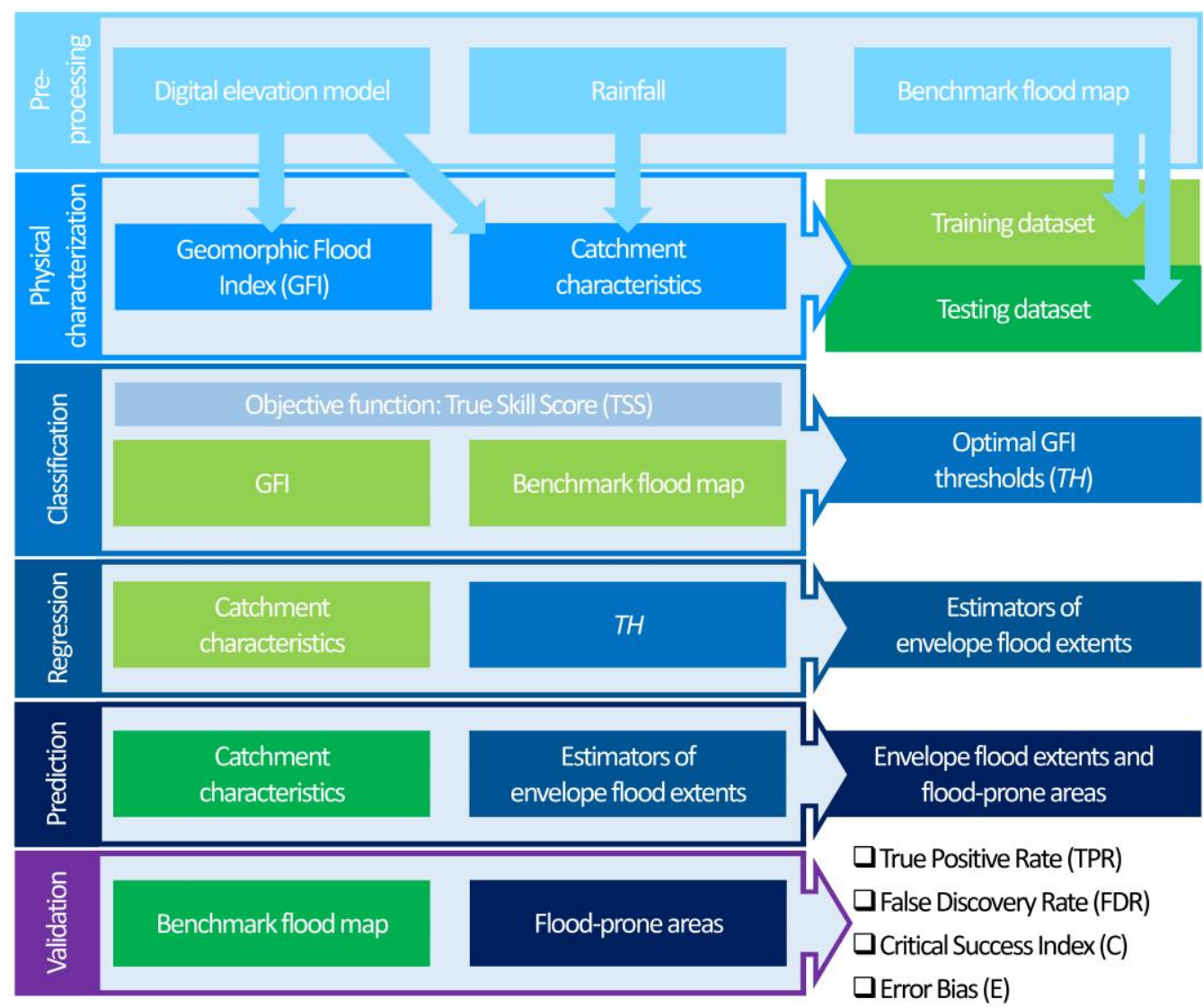

Figure 1. Workflow for developing predictive models of envelope flood extents using geomorphic and climatic-hydrologic catchment characteristics.

\subsection{Catchment delineation}

The delineation of elementary catchments accounts for a hierarchical structure that reflects the topology of the river network (Verdin and Verdin, 1999). The main reason for choosing this scale of analysis is the division of each river basin in topographic areas that may contribute significantly to discharge and that play a central role in the management of water resources. It also serves the purpose of making computations more manageable through concurrent programming (Tavares da Costa et al., 2019a). Catchments are delineated following the constraint that catchment areas should be less than ca. $1200 \mathrm{~km}^{2}$.

2.2 Geomorphic and climatic-hydrologic catchment characterization

Catchment characteristics used in this study as explanatory variables (see Table 1) are strictly geomorphic and climatic-hydrologic, as defined by Horton (1932), where soil, geology and vegetation are not taken into account. For consistency, the same high-resolution DEM of the proprietary flood maps is used to extract geomorphic catchment characteristics.

Table 1. Summary of geomorphic and climatic-hydrologic catchment characteristics.

\begin{tabular}{|l|l|}
\hline Characteristics & Description \\
\hline$A$ & Area of elementary catchment $\left(\mathrm{km}^{2}\right)$ \\
\hline$F$ & Flow accumulation at the elementary catchment outlet $(-)$ \\
\hline$\Delta z$ & Relief of elementary catchment $(\mathrm{m})$ \\
\hline$S$ & Relief-area ratio of elementary catchment $\left(\mathrm{m} \mathrm{km}^{-2}\right)$ \\
\hline
\end{tabular}




\begin{tabular}{|c|c|}
\hline$L_{c h}$ & Total river channel length in elementary catchment $(\mathrm{km})$ \\
\hline$\Delta z_{c h}$ & Relief of the river channel in elementary catchment (m) \\
\hline$S_{c h}$ & Relief ratio of the river channel in elementary catchment $\left(\mathrm{m} \mathrm{km}^{-1}\right)$ \\
\hline$P_{10}$ & $\begin{array}{l}10 \text { consecutive days precipitation at the elementary catchment scale } \\
\text { associated with the } 10 \text {-year return period }\left(\mathrm{mm} \mathrm{yr}^{-1}\right)\end{array}$ \\
\hline$P_{10 k}$ & $\begin{array}{l}10 \text { consecutive days precipitation at the elementary catchment scale, } \\
\text { associated with the } 10,000 \text {-year return period }\left(\mathrm{mm} \mathrm{yr}^{-1}\right)\end{array}$ \\
\hline$M A P$ & Mean annual precipitation in elementary catchment $\left(\mathrm{mm} \mathrm{yr}^{-1}\right)$ \\
\hline$q 10$ & $\begin{array}{l}\text { Unit discharge at the elementary catchment outlet for the } P_{10} \text { statistic }\left(\mathrm{m}^{3}\right. \\
\left.\mathrm{s}^{-1} \mathrm{~km}^{-2}\right)\end{array}$ \\
\hline$q 10 k$ & $\begin{array}{l}\text { Unit discharge at the elementary catchment outlet for the } P_{10 k} \text { statistic } \\
\left(\mathrm{m}^{3} \mathrm{~s}^{-1} \mathrm{~km}^{-2}\right)\end{array}$ \\
\hline$q_{M A P}$ & $\begin{array}{l}\text { Unit discharge at the elementary catchment outlet for the MAP statistic } \\
\left(\mathrm{m}^{3} \mathrm{~s}^{-1} \mathrm{~km}^{-2}\right)\end{array}$ \\
\hline
\end{tabular}

The following single geomorphic catchment characteristics were considered: area of elementary catchment $(A)$; flow accumulation at the elementary catchment outlet $(F)$, defined as the cumulative sum of raster cells upstream of the outlet, which relates to $A$; relief of the elementary catchment $(\Delta z)$ defined as:

$$
\Delta \mathrm{z}=\mathrm{z}_{\max }-\mathrm{z}_{\min },
$$

with $z_{\max }$ the maximum and $z_{\min }$ the minimum elevation of the elementary catchment; the total river channel length in the elementary catchment $\left(L_{c h}\right)$, which also relates to $A$; and mean river channel fall, or relief, in the elementary catchment $\left(\Delta z_{c h}\right)$ :

$$
\Delta \mathrm{z}_{c h}=\mathrm{z}_{\text {ch,max }}-\mathrm{z}_{\text {ch, } \min },
$$

with $z_{c h, \max }$ the maximum and $z_{c h, \min }$ the minimum elevation of the stream channel in the corresponding elementary catchment. Single geomorphic catchment characteristics were chosen according to their relevance as potential drivers of flood (e.g., Gaál et al, 2012). The magnitude of a flood can be related to $A$, and $F$, as it conditions the amount of precipitation that may enter a catchment, that is intercepted by vegetation, infiltrates the soil or is routed to the stream channel. On the other hand, catchment relief $(\Delta z)$ determines whether water infiltrates or flows quickly to a stream channel. In turn, channel relief $\left(\Delta z_{c h}\right)$ determines whether water flows quickly to the outlet or accumulates and leads to a flood. Finally, stream channel length $\left(L_{c h}\right)$, in combination with $\Delta z_{c h}$, determines whether travel times of water are shorter or longer and the amount of storage, this affects the response of a catchment to precipitation.

Composite geomorphic catchment characteristics used in this study are representative of the mean declivity. Within each elementary catchment, the relief-area ratio is defined as:

$$
\mathrm{S}=\frac{\Delta z}{A}
$$

while the relief ratio of the river channel in the elementary catchment is defined as:

$$
\mathrm{S}_{c h}=\frac{\Delta z_{c h}}{L_{c h}} \text {. }
$$

From a hydrological perspective, relief-area ratio has an important relation to surface runoff, to the concentration of rainfall in river channels and to flood magnitude (Horton, 1932). On the other hand, relief ratio of the river channel gives an estimate of channel storage and time length required by a flood wave to traverse the channel (Horton, 1932), while it also relates to the linear head loss found in the Manning's equation for uniform flow (Manning, 
1891). High mean declivities equate to water entering the channel quicker, and thus to higher flooding likelihood. By contrast, gentle sloping channels are slower to route the incoming runoff and have a lower flooding likelihood.

Precipitation is the most important factor driving a flood. In particular, multi-day rainfall events are an important cause of flooding (Fowler \& Kilsby, 2003) as they increase the likelihood of exceeding the catchments drainage capacity. In this study, the annual highest 10 consecutive day precipitation is reported, which has a likelihood of occurring or of being exceeded every 10 and 10,000 years on average ( $P_{10}$ and $P_{10 k}$, respectively). These statistics were calculated based on the ECA\&D E-OBS 0.1 degree regular gridded precipitation dataset (Cornes et al., 2018). Principal component analysis was applied to precipitation anomalies in the dataset for the 1950-2010 period, in order to identify dominant rainfall patterns across Europe. Stochastic precipitation fields were obtained for 50,000 years as linear combinations of empirical orthogonal functions and principal components (Zanardo et al., 2019). To complement these statistics, the mean annual precipitation (MAP) calculated by averaging the annual totals obtained from the ECA\&D E-OBS dataset is also reported.

Proxies for long-term average runoff are obtained by accumulating precipitation statistics downstream using the hierarchy of connected elementary catchments. The general water balance equation for each elementary catchment is given by:

$$
P+\Delta Q-E-\Delta W_{S}=0
$$

with $P$ the precipitation received at each elementary catchment, $\Delta Q$ the change in specific runoff, $E$ the evapotranspiration and $\Delta W_{S}$ the change in water storage. If subsurface water flow and evapotranspiration losses are neglected as a simplification for severe rain storms and very humid conditions - meaning that overland flow suffers either from saturation excess or infiltration excess and that evapotranspiration losses are much lower than water entering the elementary catchment - the direct conversion of precipitation into runoff may be assumed dominant at each elementary catchment, water yield tends to 1 , and the following equation holds:

$$
Q_{\text {out }}=P+Q_{\text {in }},
$$

with $Q_{\text {out }}$ the runoff at each elementary catchment outlet and $Q_{\text {in }}$ the runoff from upstream elementary catchments. Equation 6 can be further expanded, to cater for the lumped cascading estimation of direct runoff at the elementary catchment:

$$
Q_{\text {out }}=P_{0} * A_{0}+\sum_{i=1}^{n} P_{i} * A_{i},
$$

with $P_{0}$ corresponding to a unique long-term average precipitation statistic (i.e., $P_{10}, P_{10 k}$ or $M A P)$ associated with the elementary catchment under analysis with area $A_{0}$, while $P_{i}$ is the unique precipitation statistic associated with the n-th upstream elementary catchment with area $A_{i}$. Results are reported as unit discharge at each elementary catchment outlet:

$$
q_{\text {out }}=\frac{Q_{\text {out }}}{F * \text { cell size }},
$$

with cell size (in $\mathrm{m}^{2}$ ) equal to the product of pixel length by pixel width, specific to each DEM.

Spurious values found in the computed catchment characteristics were filtered out. In specific, some elementary catchments were found to be unrealistically small $\left(A<2 \mathrm{~km}^{2}\right)$, this was due to automatic delineation problems, namely polygon intersections and invalid geometries, and some of the precipitation statistics presented a number of values that deviated markedly from the other data points. 


\subsection{Flood descriptor}

A flood descriptor is understood here as a raster layer that is able to identify the susceptibility to flooding in a given area. It can be obtained by combining different factors into a unique raster layer (e.g., terrain analysis, land use and land cover, and so forth). In this study, the flood descriptor, GFI, is presented as a combination of hydrogeomorphic factors (Samela et al., 2017). The GFI computation requires several steps (Tavares et al., 2019a).

\subsubsection{Terrain analysis}

The extraction of the terrain analysis layers from the DEM for each European river basin precedes the computation of the GFI. Terrain analysis employed in this work follows a simple workflow (see supporting information Figure S2 for an illustration of this workflow) using the TauDEM toolbox (Tarboton, 2015). For more details, the reader can refer to Tavares da Costa et al. (2019a, b).

\subsubsection{The Geomorphic Flood Index}

The GFI is a raster layer estimated from pre-processed terrain analysis layers extracted from a DEM. The computation of the GFI for each of the major river basins in Europe considered in this study is given by:

$$
G F I_{i j}=\ln \left(\frac{h_{i j}}{H_{i j}}\right) \text {. }
$$

It is composed of two terms, computed following the steepest downslope path given by a convergent eight direction flow model (abbreviated as D8 flow model). The first term, $h_{i j}$ (in meters), consists of an empirically derived bankfull depth estimated by means of a power law hydraulic scaling relation of bankfull depth and upslope contributing area (Nardi et al., 2006; Dodov \& Foufoula-Georgiou, 2006; Manfreda et al., 2015; Samela et al., 2016, 2017). The empirically derived bankfull depth in each cell under analysis $(i, j)$ is computed using the upslope contributing area specific to the river centreline cell hydrologically connected to cell $i, j$ following the D8 flow model:

$$
h_{i j}=a\left(A_{k}^{c h}\right)^{n} \text {, with } A_{k}^{c h}=F_{k}^{c h} * \text { cell size } .
$$

with $F$ the flow accumulation specific to the river centreline cell hydrologically connected to cell $i, j$ following the D8 flow model.

For simplicity, the power law constant $a$ and exponent $n$ are kept constant with values of 0.1 and 0.4 (Samela et al., 2017), respectively. The reason for integrating a bankfull depth that scales with contributing area in the GFI is to mark a clear boundary between channel and floodplain and avoid problems with the actual channel. The second term of the GFI consists of the HAND calculated between the cell under analysis $(i, j)$ and the river centreline cell hydrologically connected to cell $i, j$, following the D8 flow model:

$$
H_{i j}=z_{i j}-z_{k}^{c h} \text {, }
$$

with $z_{i j}$ the DEM elevation value of the cell under analysis and $z_{k}^{c h}$ the DEM elevation value of the hydrologically connected river centreline cell. The HAND model makes each cell elevation value relative to the connected channel cell instead of the mean sea level. This is crucial in order to determine unique thresholds that best define a specific envelope flood extent. The GFI is rescaled before use to a range of values lying between 0 and 1 , 
corresponding to low (i.e., away from the river centreline) and high hazard levels (i.e., near the river centreline), respectively. Note that moving away from the river centreline, $H_{i j}$ increases while the GFI decreases. Scaling is achieved by resorting to the minimum and maximum values of the GFI (Tavares da Costa et al., 2019a). The rescaled GFI can effectively be used as a classifier of flood-prone areas (Manfreda et al., 2015; Samela et al., 2016, 2017; Tavares da Costa et al., 2019a) and of the extent of the envelope of major floods that is confined to the floodplain, between the active river channel at bankfull and the surrounding marked topography. The GFI computation is summarized in Figure 2.
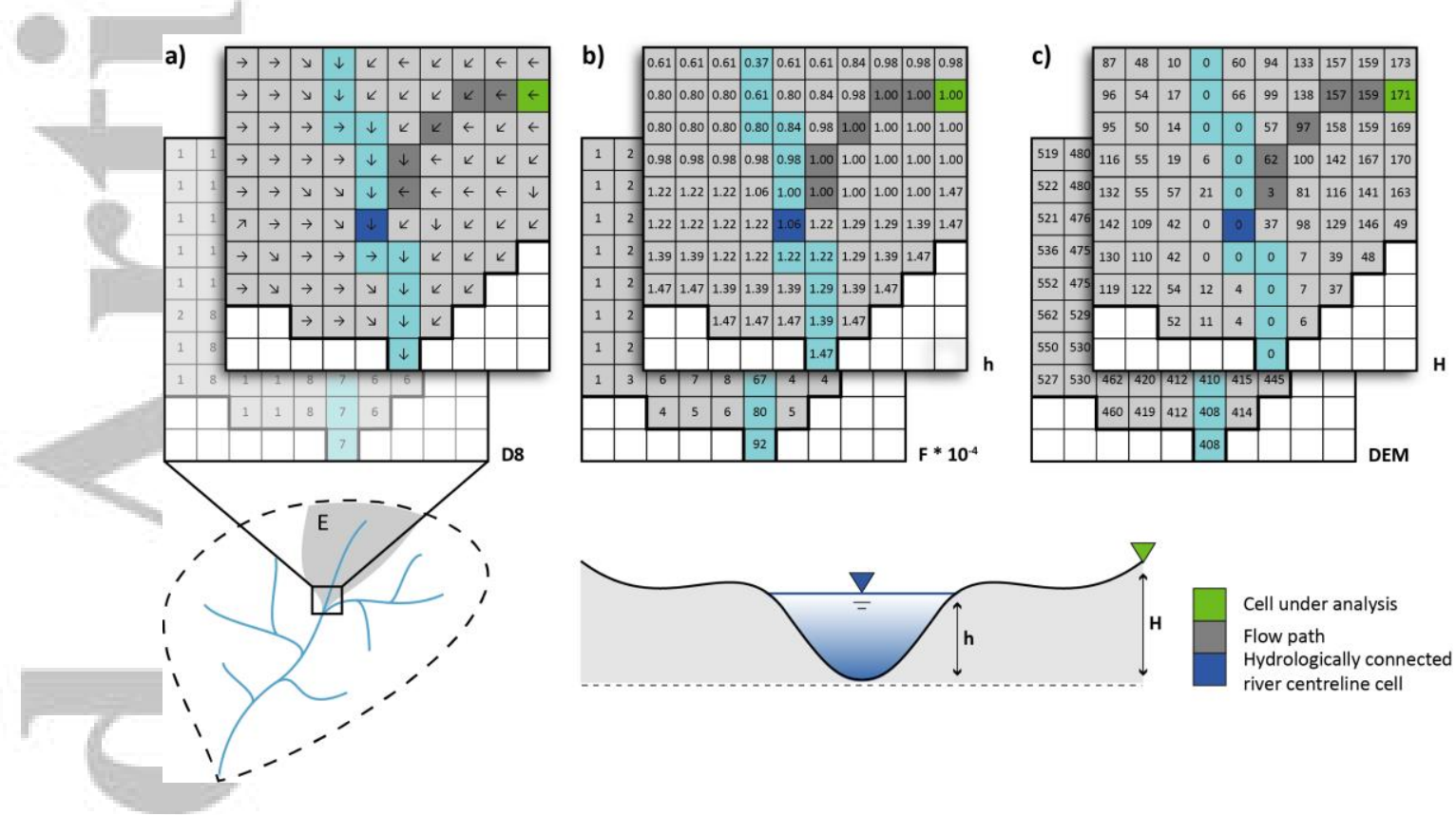

Figure 2. Description of the two components that constitute the Geomorphic Flood Index (GFI) layer. a) Representation of a D8 flow direction raster for a portion of an elementary catchment. b) The empirically derived water level in each cell under analysis computed as a power law of bankfull depth and upslope contributing area of the hydrologically connected river centreline cell. c) The DEM elevation difference between the cell under analysis and the hydrologically connected river centreline cell. At the lower left, a river basin representation showing the elementary catchment $\mathrm{E}$, in grey, and the river network, in blue. At the lower centre, a cross-section representation of the river channel and floodplain illustrating the two terms involved in the computation of the GFI for a generic flow path.

\subsection{Discrete statistical classification}

The threshold binary classification, introduced by Degiorgis et al. (2012), is adopted in this study to find the $T H$ that produce the best possible representation of the RMS flood maps, the benchmark, in terms of flood extent (see supporting information Figure S3 for an illustration of the workflow). The resulting unique $T H$ per elementary catchment of the Thames, Weser, the upper Rhine and the upper Danube river basins are subsequently used as the target variable for training the regression models.

\subsubsection{Threshold binary classifier}

The binary classifier consists of a mathematical optimization that outputs the best possible representation of known binary values from a benchmark. The algorithm starts by creating, through image segmentation of the GFI, a binary flood extent representation associated to each threshold, out of a large number of possible values from zero to one, 
hereinafter called the segmented GFI. The algorithm then searches all these binary cases to find the one that best approximates the benchmark. The optimal case, represented by a unique $\mathrm{TH}$, is indicated by the maximization of a specific objective function that expresses the correctness of a representation.

The classifier performs better when binary categories (flood-prone and flood-free) are symmetrically distributed (Kubat et al., 1998), i.e., when raster cells of one binary class are not much greater in number than the other (i.e, class imbalance). Therefore, a portion of the GFI, namely a classification area corresponding to a fixed buffer (ca. $1 \mathrm{~km}$ ) around the river network centreline of the largest benchmark, is adopted in order to handle class imbalance by discarding the number of flood-free raster cells in excess.

The classification results are evaluated with two specific metrics based on a $2 \times 2$ binary contingency matrix (see supporting information Table S1 for an example of such matrix) that is constituted by values of: $t p$ or the number of raster cells marked as flood-prone in both the segmented GFI and the benchmark flood hazard maps; $f n$ or the number of raster cells marked as flood-free in the segmented GFI but marked as flood-prone in the benchmark; tn or the number of raster cells marked as flood-free in both the segmented GFI and the benchmark; and, $f p$ or the number of raster cells marked as flood-prone in the segmented GFI but marked as flood-free in the benchmark. The first of these metrics assesses the discerning capability of the GFI itself (the receiver operating characteristic, or ROC analysis, see section 2.4.3) while the other measures the degree of association between flood-prone areas resulting from the threshold binary classification and a benchmark (the $r_{\phi}$, see section 2.4.4). Both metrics were found to work well for this type of classification (Tavares da Costa et al., 2019a).

\subsubsection{Objective function}

The maximization of the True Skill Statistic (TSS) (Peirce, 1884) is adopted in this study as the classification rule that defines which threshold is optimal to select for each elementary catchment. The TSS represents the point of maximum forecast value of the classifier; in other words, it is the point in the ROC that has the maximum perpendicular distance from the line of no-skill (Manzato, 2007), which translates to a good representation of the binary categories in the benchmark (see supporting information Figure S4 for an example of a ROC and the respective TSS point identified in the curve).

The TSS, also based on the contingency matrix, has been used elsewhere with success by several authors (Bartholmes et al., 2009; Alfieri et al., 2012) and can also be interpreted as the probability of making an informed decision in terms of the proportion of correct binary categories, assuming for this specific study that the misclassification of flood-prone areas is as undesirable as the misclassification of flood-free areas. The TSS is defined as:

$$
T S S=\mathrm{TPR}-\mathrm{FPR}=\frac{t p}{t p+f n}-\frac{f p}{f p+t n}=\frac{t p * t n-f p * f n}{(t p+f n) *(f p+t n)},
$$

with $T P R$, the true positive rate or the probability of a correct hit; and, FPR the false positive rate or the probability of an incorrect hit. The TSS is negative when the segmented GFI has a higher number of $f p$ and $f n$ than $t p$ and $t n$; it is positive when the opposite happens, with $T S S=1$ indicating that the segmented GFI perfectly matches the benchmark. The case of $T S S=0$ implies that the classifier does not provide any useful information. 


\subsubsection{ROC analysis}

ROC analysis has been used by several authors to distinguish between decision values in a classifier and their trade-offs between costs and benefits (Bradley, 1997; Fawcett, 2006; Schumann et al., 2014b). It is considered a threshold-independent performance measure, as points falling along the ROC curve (see Figure S4 for an example) represent unique evaluations, in terms of $T P R$ and $F P R$, of a considered segmented GFI against the benchmark. The top left corner of the ROC space represents the perfect classification, such that $T P R=1$ and FPR $=0$; instead, the diagonal line dividing the ROC space represents the line of no-skill.

In the specific context of this study, the Area Under the ROC Curve (AUC) summarizes the overall discerning capability of the GFI in a single threshold-independent value per elementary catchment. As such, irrespective of the threshold, it represents the probability of correctly classifying a randomly chosen raster cell as flood-prone rather than incorrectly classifying it as such (Bradley, 1997; Fawcett, 2006). The AUC can be estimated by trapezoidal rule approximation of the definite integral and may take values from $A U C=$ 0.5 , meaning no discerning capability of the GFI, to $A U C=1$, the perfect classifier. An $A U C \leq 0.5$ is used to filter out elementary catchments that are not well suited to serve as a classifier and may therefore impact the formulation of the statistical relationships.

\subsubsection{Degree of association}

The modified Pearson's correlation coefficient for discrete dichotomous problems, $r_{\phi}$ (Cramér, 1999; Matthews, 1975), is used as a measure of magnitude of association and direction of the linear relationship between flood-prone areas and a benchmark:

$r_{\phi}=\sqrt{\frac{\chi^{2}}{N}}=\sqrt{T S S *\left(\frac{t p}{t p+f p}-\frac{f n}{f n+t n}\right)}=\frac{t p * t n-f p * f n}{\sqrt{(t p+f p) *(t p+f n) *(t n+f p) *(t n+f n)}}$,

(13)

where $\chi^{2}$ is the Pearson chi-square statistical test (Pearson, 1900), with $N$ the total number of samples. It can be seen as the geometric mean of the TSS and its complementary term. The $r_{\phi}$ is used in this study to evaluate the degree of association between the segmented GFI and the benchmark. As a rule of thumb, it is assumed that values between 1 and 0.5 represent a strong positive degree of association, between 0.5 and 0.3 a moderate degree of association, 0.3 to 0.1 a weak degree of association and from 0 to 0.1 a complete absence of association. A $r_{\phi} \leq$ 0.3 is used to filter out elementary catchments that have a weak degree of association.

\subsection{Formulation of statistical relationships}

Multivariate statistical methods can be used to describe the relationship between unique $T H$, the target variable, and a set of explanatory variables represented by catchment characteristics that are scaled and mean centred before use. In this study, the stepwise regression and random forest are setup as models to predict envelope flood extents.

\subsubsection{Stepwise regression}

Multiple linear regressions (MLR) are well-established models in hydrological sciences, particularly between flood moments and catchment characteristics (Merz \& Blöschl, 2005; Haddad et al., 2012).

Ideally, catchment characteristics should not be highly correlated to each other or to their linear combination, since multicollinearity may increase the variance of parameter 
estimates and potentially lead to unreliable results. Therefore, before developing the statistical models, multicollinearity is diagnosed with the variance inflation factor $(V I F)$. Multicollinearity may be present when VIF > 10 (Hirsch et al., 1992; Merz \& Blöschl, 2005) and therefore variables above such values are considered for elimination prior to model fitting.

The problem of estimating the regression coefficients, or the fitting problem, is solved by stepwise analysis with bidirectional elimination (i.e., the sequential addition) and replacement or elimination of explanatory variables based on the relative quality of each competing model. The trade-off between maximum likelihood and explanatory variables, or model's simplicity in this context, is measured by the Akaike's information criterion (AIC) (Akaike, 1974). In practical terms, model selection is based on the minimum possible AIC obtained for competing models (Haddad et al., 2012). A formal definition of MLR, VIF and $A I C$ can be found in supporting information.

To obtain classical evaluation metrics such as $R^{2}$ and the root mean square error (RMSE), a 10-fold cross-validation procedure is used. The cross-validation consists of randomly splitting the dataset in ten equally-sized groups, one of which is retained for testing and the remaining are used for training. The training and testing procedures are repeated ten times, until every single group has been selected once. Performance results from each of the ten validations are averaged to produce a single final estimation.

\subsubsection{Random forest}

Random forest (Breiman, 2001; Breiman \& Cutler, 2007) is a rule-based machine learning method that can be used for classification (Wang et al., 2015; Coltin et al., 2016) or regression (Iorgulescu \& Beven, 2004; Pappenberger et al., 2006; Prieto et al., 2019). A formal definition of random forest can be found in supporting information.

Some important advantages of the random forest method are that it does not need any specific assumption about the probability distribution (non-parametric), it works well when the relationship between explanatory variables and response is non-linear, as well as when there are high order interactions (Snelder et al., 2013). Furthermore, random forest is relatively robust against outliers, noise and overfitting (Breiman, 2001) and can handle the problem of multicollinearity well (Cutler et al., 2007).

As opposed to MLR, a chief disadvantage of this method is that it cannot predict target values outside the range of the explanatory variables in the training dataset. Another limitation of the random forest is that it does not provide an easy understanding of the statistical relationships between explanatory variables. Even though, it does provide a simple visualization of the model structure and of the covariate influence, in contrast to other machine learning methods, such as artificial neural networks (Shortridge et al., 2016).

The random forest regression model used in this study goes through an automatic and distributed optimization procedure (grid search) of the setup parameters in order to find the best performing model, in terms of both accuracy and computational efficiency. In specific, the optimized parameters are the number of decision trees in the ensemble, the number of sampled variables at each tree node and the maximum depth of each tree. The optimization of the random forest regression is achieved a priori, using a 10-fold cross-validation to obtain evaluation metrics and compare the multiple models.

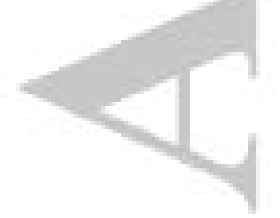




\subsection{Performance assessment}

To evaluate the fit between predicted flood-prone areas, obtained through image segmentation of the GFI using the predicted $T H$, and the benchmark, four common performance metrics, also based on the contingency matrix, are selected in order to keep consistency with other published works (e.g., Wing et al., 2017; Jafarzadegan and Merwade, 2017). These are the hit rate, or $T P R$, as described in section 2.4.2; the false discovery rate:

$F D R=\frac{f p}{f p+t p}$

with values ranging from $F D R=0$ (no false alarms) to $F D R=1$ (overprediction); the critical success index:

$C=\frac{t p}{t p+f n+f p}$

(15)

with values ranging from $C=0$ when there is no match between the delineated flood-prone areas and the benchmark and $C=1$ when there is a perfect match; and the error bias:

$E=\frac{f p}{f n}$

(16)

that indicates whether there is a tendency towards underprediction, $0 \leq E<1$, or overprediction, $E>1$, with $E=1$ an indication of no bias.

As the objective is to predict envelope flood extents, overpredicting the flood-prone areas might benefit the $t p$ and inflate the TPR. This inflation would be of concern if there was no other reported measure that would give an alternative account of the performance. By reporting the $F D R$, an account of the percentage of cells that are overpredicted is given. At the same time, the critical success index extends the $T P R$ by including the $f p$, accounting for both under- and overprediction, while the error bias gives the ratio between the $f p$ and the $f n$ indicating whether there is a tendency for under- or overprediction. The reporting of these four measures should give a reasonable overall account of the performance.

\section{Study Area, Data Sources, Training and Test Sets}

The River Thames in the UK constitutes the longest one in southern England (ca. 350 $\mathrm{km}$ length). It drains an area (ca. 13,478 $\mathrm{km}^{2}$ ) of relatively flat terrain (mean elevation of ca. $100 \mathrm{~m}$ a. s. 1.) to the North Sea. The Thames river basin has a MAP ranging from ca. 610 to $778 \mathrm{~mm} \mathrm{yr}^{-1}$ that results in a mean annual runoff (MAR) ranging from 100 to $295 \mathrm{~mm} \mathrm{yr}^{-1}$. The Thames is prone to major flooding; the 2013/14 winter floods that the valley sustained are an example of this (Huntingford et al., 2014; Fenn et al., 2016).

The River Weser in Germany has an overall length of ca. $452 \mathrm{~km}$. It drains an area of (ca. $43,857 \mathrm{~km}^{2}$ ) relatively flat terrain (mean elevation of ca. $200 \mathrm{~m}$ a. s. 1.) to the North Sea. The Weser river basin has a MAP ranging from ca. 575 to $1,195 \mathrm{~mm} \mathrm{yr}^{-1}$ that results in a $M A R$ ranging from 190 to $930 \mathrm{~mm} \mathrm{yr}^{-1}$. In 2013, the Weser river basin was affected by high flood levels with peak discharges above the 50-year return period (Schröter et al., 2015).

The River Rhine (ca. 1,230 km total length) has its source in the Swiss Alps and flows through several major cities in Switzerland, France, Germany and the Netherlands, where it drains to the North Sea. The upper Rhine river basin (drainage area of ca. $32,114 \mathrm{~km}^{2}$ ), the portion of the Rhine river basin considered in this study, presents a relatively mountainous terrain (mean elevation of ca. 1,065 m a. s. 1.), with MAP ranging from ca. 825 to $1,715 \mathrm{~mm}$ 
$\mathrm{yr}^{-1}$ and resulting MAR ranging from 330 to 2,250 $\mathrm{mm} \mathrm{yr}^{-1}$. The upper Rhine river basin is prone to major flooding; for example, in 2007, one person lost its life, at least 100 were affected and the country withstood a total estimated damage of more than 312 million EUR (CRED EM-DAT).

Originating in Germany and flowing through major cities (e.g., Vienna in Austria) in 10 different countries before draining to the Black Sea, the River Danube is the second longest river in Europe (ca. 2,850 km length). The upper Danube river basin (drainage area of ca. $97,000 \mathrm{~km}^{2}$ ), portion considered in this study, is characterized by a relatively mountainous terrain (mean elevation of ca. $890 \mathrm{~m}$ a. s. 1.), MAP ranging from ca. 460 to $1,785 \mathrm{~mm} \mathrm{yr}^{-1}$ and resulting $M A R$ ranging from ca. 23 to $1,282 \mathrm{~mm} \mathrm{yr}^{-1}$. The upper Danube river basin is prone to major flooding; for example, in 2013, four persons lost their lives, at least 200 were affected and the country withstood a total estimated damage of more than 893 million EUR (CRED EM-DAT).

The River Rhône in France originates in the Swiss Alps and runs through south-eastern France, where it finally drains to the Mediterranean Sea. The Rhône river basin, with an area of ca. $96,475 \mathrm{~km}^{2}$ has a mean elevation of ca. $785 \mathrm{~m}$ a. s. 1 . It is characterized by a MAP ranging from ca. 561 to $1,890 \mathrm{~mm} \mathrm{yr}^{-1}$, resulting in a $M A R$ ranging from ca. 119 to $1,551 \mathrm{~mm}$ $\mathrm{yr}^{-1}$. The winter floods of 2003 marked the largest flood in the Rhône river basin since 1856 . Consequences arising from this event were severe, with the country withstanding a total estimated damage of ca. 1.130 billion EUR (Arnaud-Fassetta, 2013). Mean elevation values presented in this section were estimated from the EEA EU-DEM, MAP values from the ECA\&D E-OBS and MAR values from the UNH/GRDC runoff dataset (Fekete et al., 2002).

The five river basins were selected for this study mostly for their record of major floods and their importance in Europe; their geographical locations can be visualized in Figure 3. The GFI raster layer and the catchment characteristics are computed for all selected river basins using a proprietary DEM dataset, hereafter referred to as RMS-DEM, at ca. $50 \mathrm{~m}$ spatial resolution. The RMS-DEM is suited for flood inundation modelling, as it does not contain artefacts such as trees, buildings or bridges that can adversely affect the accuracy of the simulations. The (1) Thames river basin in the UK, with 83 elementary catchments delineated, the (2) Weser river basin in Germany, with 170 elementary catchments delineated, the (3) upper Rhine river basin in Switzerland, with 109 elementary catchments delineated, and the (4) upper Danube river basin in Austria, with 286 elementary catchments delineated, are used for training the regression models. Their merging into a single dataset resulted in a total of 648 elementary catchments for each return period, of which, after filtering out issues such as poor classification results (see sections 2.2, 2.4.3 and 2.4.4 for more details), 453 were effectively used for the 10-year return period and 486 for the 10,000 year return period, giving a total of 939 data points effectively used and 357 discarded. The first two river basins are representative of flatter regions and the last two of mountainous regions. The (5) Rhône river basin in France, with 277 elementary catchments delineated, is instead used for testing the regression models. 


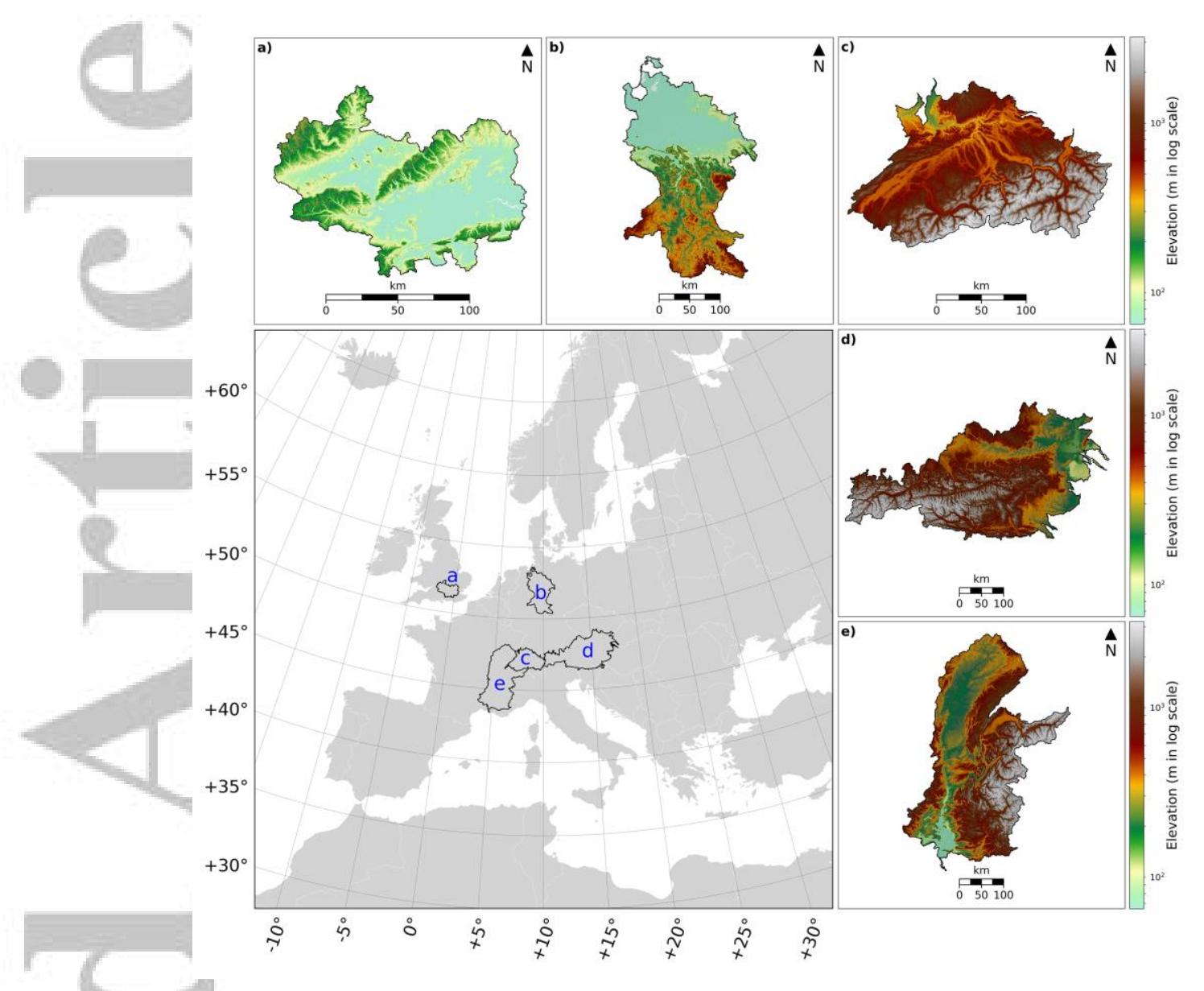

Figure 3. Study area comprising five major European river basins, with drainage divide highlighted in black in the lower left map. The training of the regression models is performed using four river basins, namely a) the Thames river basin in the UK, b) the Weser river basin in Germany. c) the upper Rhine river basin in Switzerland, and d) the upper Danube river basin in Austria. Testing of the regression models is performed using e) the Rhône river basin in France.

The benchmarks used in the threshold binary classification to find the unique $T H$ values, and also in the evaluation of the final predictions, are high-resolution flood hazard maps for Europe, developed by RMS and currently used by global insurance and reinsurance companies. The RMS flood maps were created for several return periods at ca. $50 \mathrm{~m}$ resolution. They are based on a cascade of sequential modelling components. Rainfall runoff processes are modelled with a semi-distributed, TOPMODEL-based approach (Beven \& Kirkby, 1979). Flows are routed through the river network using the Muskingum-Cunge 1D wave propagation method (Cunge, 1969; Georgakakos et al., 1990). Inundation depths and extents are derived by applying rating curves to river flows in every river segment of $500 \mathrm{~m}$, calculating the associated river depth and filling the river cross-section extracted from the DEM for each segment. The maximum flood depths over the floodplain, after propagating the flood wave through the main river channel, represent the flood hazard map for an event. The benchmarks are used in the form of binary masks (raster cells marked as flood-prone or flood-free) obtained through image segmentation with a cut-off depth set to $0.01 \mathrm{~m}$. The overall accuracy of the benchmarks is not expected to be very high because of the methodology employed; however, they should provide a fairer comparison, since the GFI is not able to represent the dynamics of the flow over the floodplain. 


\section{Results}

4.1 Classification outcomes and catchment characteristics

The classification of the GFI layer to obtain the $T H$ was performed using each elementary catchment that constitutes the training set, composed of four major river basins in Europe. In Figure 4, the data used in the development of estimators and prediction of envelope flood extents for the 10- and 10,000-year return periods is presented.
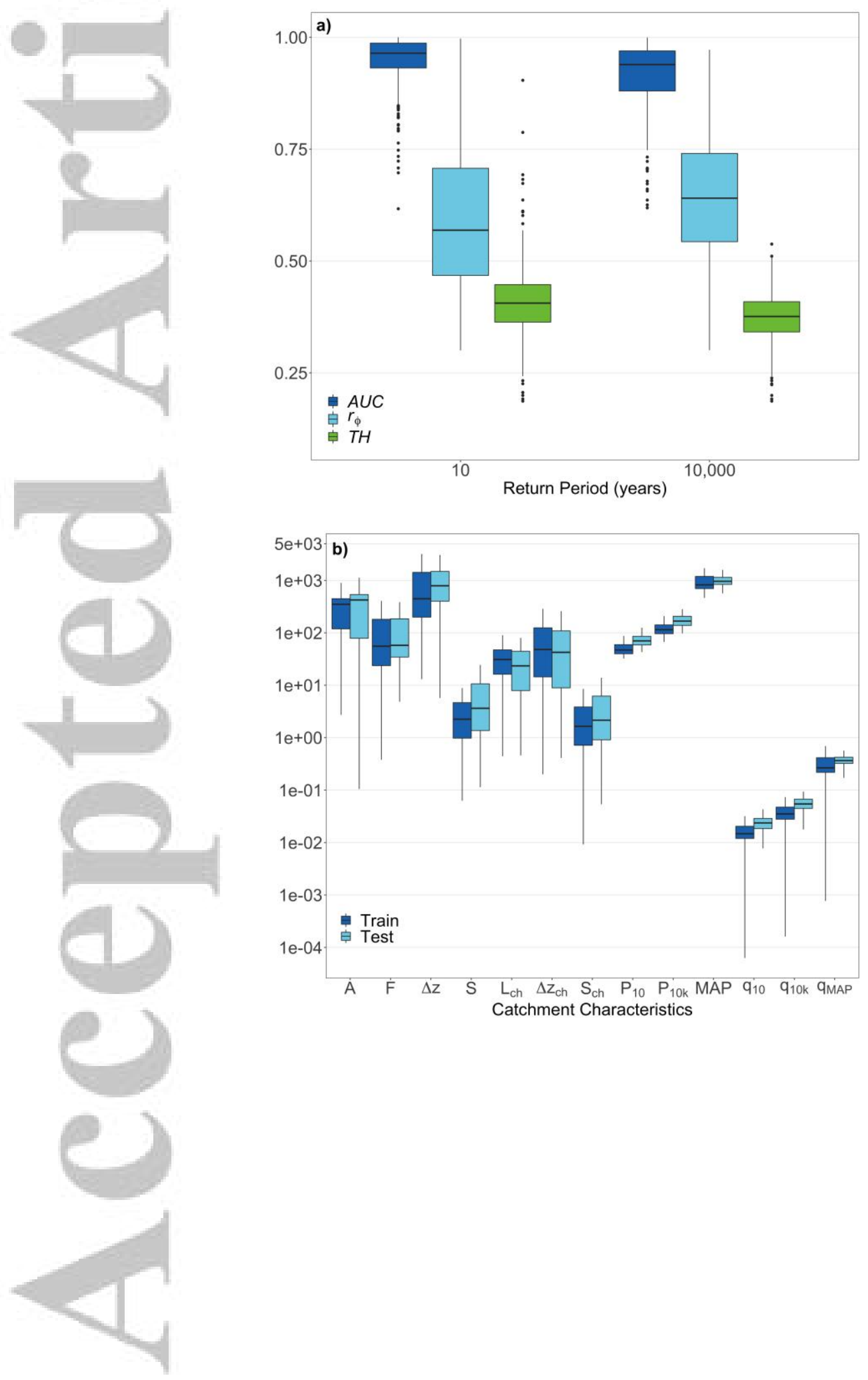


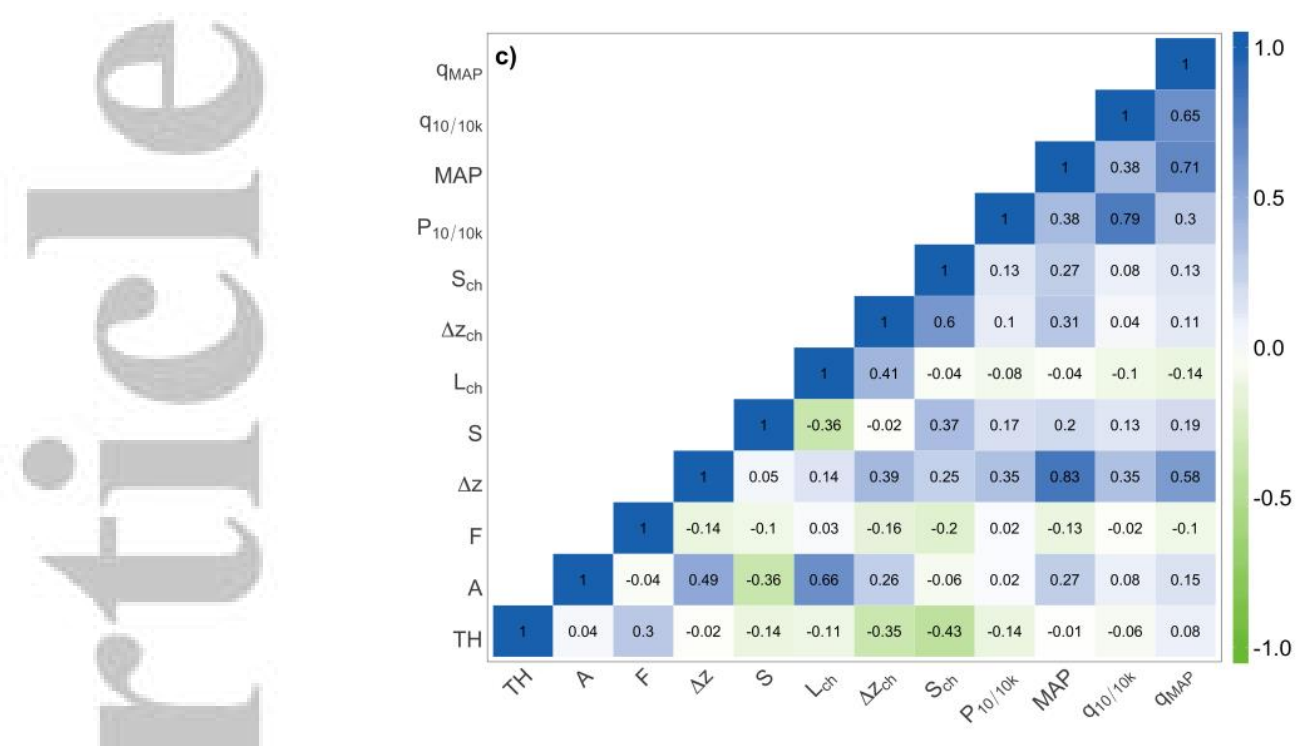

Figure 4. Data used in the development of estimators and prediction of envelope flood extents for the 10- and 10,000-year return periods, please refer to Table 1 and section 2.2 for a complete description and units of variables. a) Area Under the relative operating characteristic Curve AUC the modified Pearson's correlation coefficient for discrete dichotomous problems $r_{\phi}$ and the optimal Geomorphic Flood Index (GFI) thresholds $T H$ obtained from the classification of training catchments (Thames, Weser, upper Rhine and upper Danube river basins). b) Geomorphic and climatic-hydrologic catchment characteristics for the combined training and test catchments (Rhône river basin). c) Correlation matrix between $\mathrm{TH}$ and catchment characteristics.

Average $A U C$ values of ca. $95 \%$ and $91 \%$ are found for the 10 and 10,000-year return periods, respectively, which indicates a very high discerning capability of the GFI classifier. These $A U C$ values translate to a high probability of correctly classifying a raster cell as floodprone or flood-free.

Average $r_{\phi}$ values between ca. $60 \%$ and ca. $64 \%$ are found for the 10- and 10,000year return periods, respectively, which indicates a strong positive degree of association (i.e., between 1 and 0.5 ) of the best possible representation of flood-prone areas.

Values of $T H$ for the elementary catchments of the training set are found to range between 0.18 and 1 , with a mean value of ca. 0.44 and 0.39 for the 10 - and 10,000-year return periods, respectively. As expected, there is a tendency towards a value decrease with increasing return period (Tavares da Costa et al., 2019a).

For most catchment characteristics more than $50 \%$ of test data is contained within the training set interquartile range. Exceptions to this can be found for the precipitation statistics, $P_{10}$ and $P_{10 k}$, with median slightly above the test set interquartile range, and for the corresponding unit discharge estimates, $q_{10}$ and $q_{10 k}$. The sample variability of the test set is larger than that of the training set for the $A$, the $S$, the $L_{c h}$, and the $S_{c h}$. The explanatory variable $A$ is the only that is noticeably positively skewed, while the MAP and corresponding $q_{M A P}$, are negatively skewed. These differences are expected to impact the final prediction of envelope flood extents as the training set does not represent the test set in the most exhaustive manner.

The correlation matrix in Figure $4 \mathrm{c}$ provides an evaluation of the magnitude of association and direction of the linear relationship between explanatory variables and the dependent variable (in Figure S5 of supporting information the correlation matrices for the 
10- and 10,000-year return periods are presented). Correlation between the $T H$ and the $F$, indicate a moderate positive linear relationship. Moreover, a moderate negative linear relationship is revealed between $T H$, the $\Delta z_{c h}$ and $S_{c h}$. The remaining catchment characteristics reveal weak linear relationships to the $T H$.

Furthermore, correlations that exist between different catchment characteristics may be indicative of multicollinearity. Disregarding the correlations between composite explanatory variables and their constituting parts, a moderate to strong positive correlation between precipitation statistics, discharge proxies and $\Delta z$ is noticeable. Also, $A$ shows a strong positive correlation with $\Delta z$ and $L_{c h}$. Collinearity between catchment characteristics is an undesirable condition that can negatively impact the quality of the statistical relationships for the prediction of envelope flood extents and needed to be addressed before any further step is taken.

\subsection{Estimators of envelope flood extents}

Two types of regression models were built from the classification outcomes $T H$ and catchment characteristics of the training set, namely the stepwise regression and the random forest regression models.

Several data transformations were tried for building different models (log-linear, linear-log and principal component analysis, which were tested but did not produce any beneficial result). Log-log transformed variables (note that the GFI is already a logarithm) were used as they substantially improved both models' statistical tests and performance metrics.

Several data splits were also tried for building different models. For example, one model for the 10- and another for the 10,000-year return period were tried but did not yield significantly different results from the ones presented in Table 2. Furthermore, the inclusion of only some specific river basins was tested. Namely, two out of the four training river basins were held out at the time for testing the models, built with the remainders. None of the six river basin combinations $(4 ! / 2 ! *(4-2) !=6)$ significantly improved the overall performance and in most cases holding out specific river basins actually decreased it.

In the stepwise regression, multicollinearity tests point towards strong collinearity between the composite explanatory variables and their individual constituents. Additionally, $V I F$ values above 2 were found between the combined $q_{10}$ and $q_{10 k}$ and the $q_{M A P}$. Thus, the catchment characteristics $A, \Delta z, L_{c h}, \Delta z_{c h}$ and $q_{M A P}$ were considered for elimination given the results of the multicollinearity tests and taking into consideration the correlation results presented in Figure 4c.

The previous steps were followed by a stepwise selection of explanatory variables based on the $A I C$, which reflects the trade-offs between maximum likelihood and model simplicity. A very low AIC lead to the following equation:

$$
T H=0.1580-S_{c h}^{0.0631}+F^{0.0345}+S^{0.0023}-P_{10 / 10 k}^{0.0774}+M A P^{0.1267}+q_{10 / 10 k}^{0.0156} \text {. }
$$

As can be seen from Table 2, the final optimized linear model is constituted by six of the 11 original explanatory variables and is characterized by a high $F$-statistic $(>3)$ and very low $p$-value $(<0.01)$, which indicates a high degree of significance of individual explanatory variables and of the model. From the 10-fold cross-validation procedure, results a $R^{2}$ value of ca. $42 \%$, indicating a moderate explanatory power of the model, and a RMSE of 0.0597 . 
Table 2. Optimization results for the stepwise regression (swr) and the random forest regression model (rf) for simultaneously predicting the 10- and the 10,000-year return period optimal Geomorphic Flood Index (GFI) threshold (TH) using geomorphic and climatichydrologic catchment characteristics as explanatory variables.

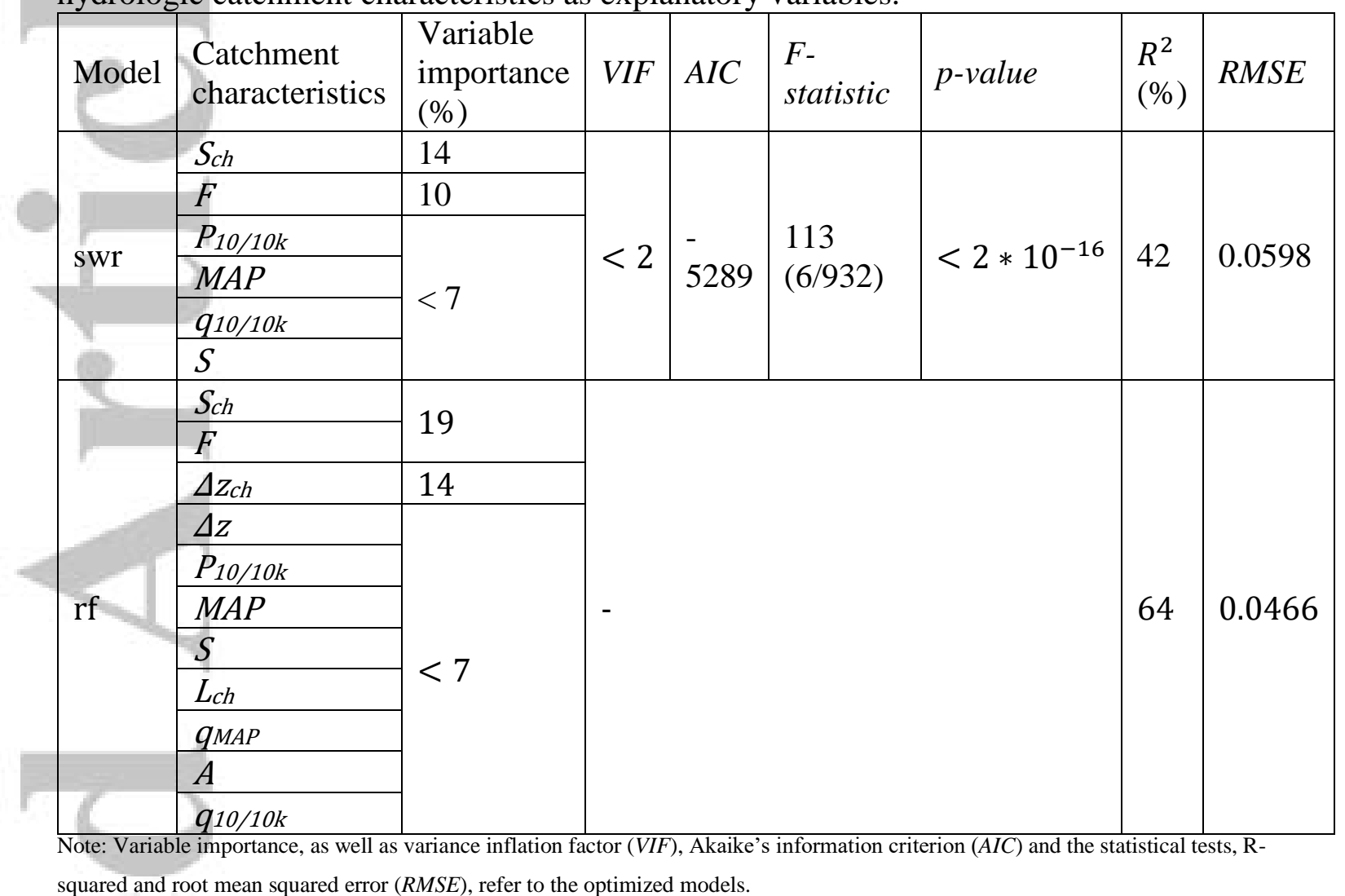

In the random forest regression, optimization was performed by an automatic search of the best possible combination of input parameters that lead to the highest possible decrease in RMSE obtained through cross-validation. This also ensured that overfitting was avoided.

The final optimized random forest regression corresponds to a model with 644 trees, three explanatory variables randomly sampled at each tree node and a maximum depth of 25 nodes. As shown in Table 2, the random forest regression results have substantially improved the explained variance obtained by the stepwise regression model, from ca. $42 \%$ to ca. $64 \% R^{2}$, and the RMSE, which decreased from 0.0598 to 0.0466 .

Variable importance was assessed based on the absolute value of the t-statistic for the MLR model (for more details about the assessment of variable relative importance in linear models please refer to Lindeman et al., 1980). For the random forest regression model, variable importance was assessed based on the empirical improvement of the squared-error as a result of a split in a non-terminal tree node, averaged over all trees (Breimen et al., 1983). It is shown that the $S_{c h}$ is the explanatory variable with the highest relative importance in both models, ca. $14 \%$ and $19 \%$, followed by the $F$ with ca. $10 \%$ and $19 \%$. In the random forest regression model $\Delta z_{c h}$ is also found to have a fairly high variable importance with ca. $14 \%$. The remaining catchment characteristics are ranked as relatively less important, or not included at all (stepwise regression). However, it should be noted, for the case of the random forest model, that as one explanatory variable is randomly selected at a tree node, the importance of other variables is substantially reduced, particularly if there is collinearity. In light of this, variable importance should be interpreted with caution, as explained in Seibert et al. (2017). 


\subsection{Prediction of envelope flood extents}

Using the models presented in the previous section, envelope flood extents were predicted based on the physical characteristics extracted for each elementary catchment of the Rhône river basin.

Catchment characteristics matching the ones used for training of the regression models were obtained for the 10- and 10,000-year return periods and used as input. A unique $\mathrm{TH}$ was predicted per elementary catchment, return period and model. The predicted $T H$ values were used to segment the original GFI raster layer of each corresponding elementary catchment of the Rhône river basin and to delineate the flood-prone areas (see Figure $5 \mathrm{~b}$ for an example).

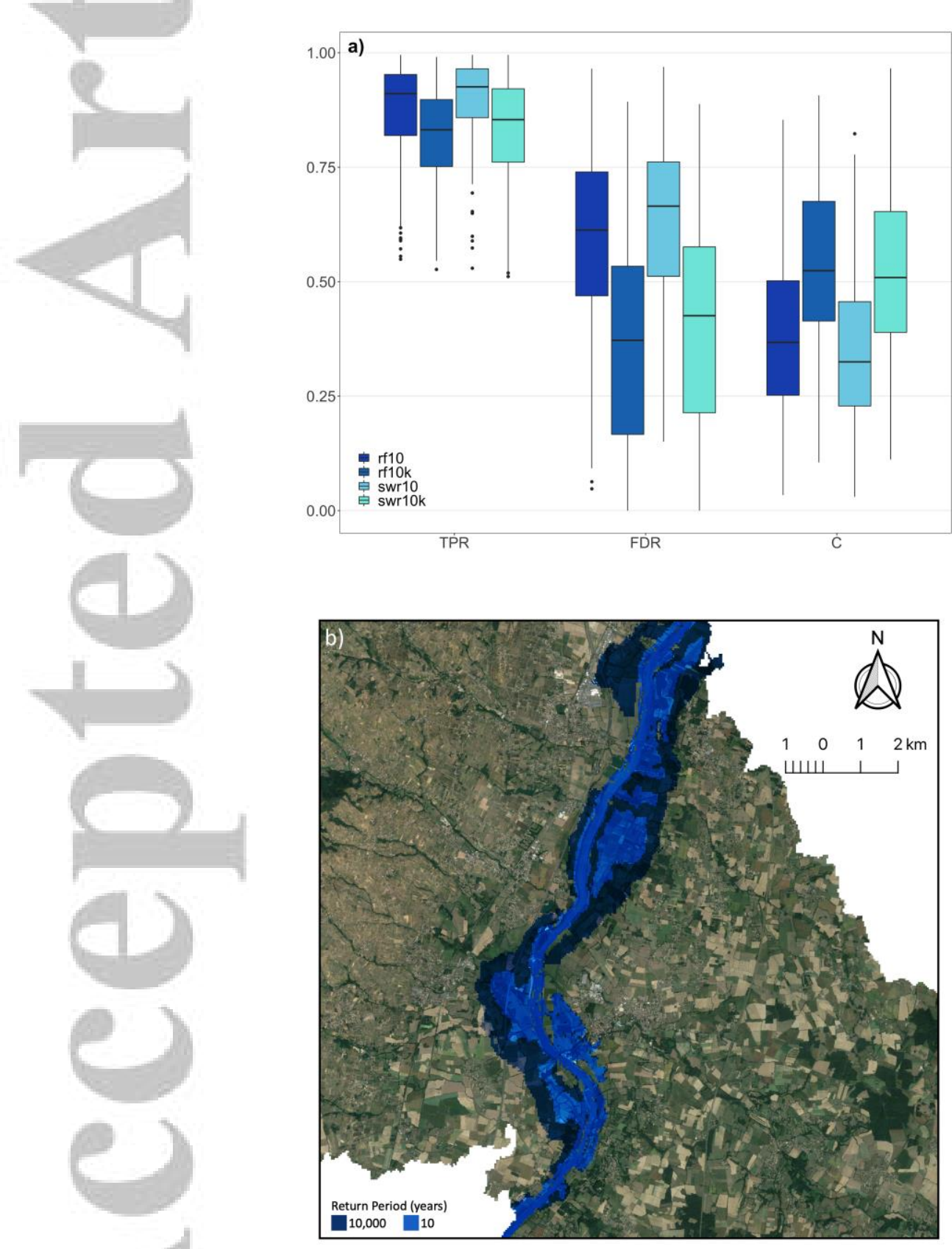

Figure 5. a) True positive rate $(T P R)$, false discovery rate $(F D R)$ and critical success index $(C)$ for the elementary catchments of the Rhône river basin, for the different regression models (rf - random forest; swr - stepwise regression) and for the 10-year and 10,000-year 
return periods. b) Overlaid samples of flood-prone areas and corresponding envelope flood extents, predicted with the rf model for two return periods at ca. $50 \mathrm{~m}$ spatial resolution.

By comparing each raster cell of the binary mask of predicted flood-prone/flood-free areas with each corresponding raster cell of the benchmark RMS flood maps, it was possible to obtain a contingency matrix for each model and for each return period considered, from which the performance metrics described in section 2.6 were computed.

In Figure 5 and Table 3, it can be observed that the $T P R$ is high for the great majority of elementary catchments (average above $80 \%$ ), similar between models and slightly higher for the 10-year return period. At the same time, the FDR is high for the 10-year return period (average ca. 63\%), moderate for the 10,000-year return period (average ca. 39\%), and slightly higher for the stepwise regression. In turn, the $C$ is moderate for the 10-year return period (average ca. 34\%), high for the 10,000-year return period (average ca. 52\%), and slightly higher for the random forest. It is also shown by the $E$ that more than ca. $85 \%$ of the floodprone areas obtained for the elementary catchments of the Rhône river basin suffer from overestimation $(E>1)$. On average, the $T P R$ decreased with increasing return period, but this seems to be compensated by a significantly lower number of false alarms, as a higher $C$ is observed for the 10,000-year return period and a decrease of $E$ (for more details see supporting information Figure S6 where the distribution of the tp, fn and fp values, in terms of absolute predicted area, are presented).

Table 3. Average performance of the regression models, expressed as true positive rate $(T P R)$, false discovery rate $(F D R)$, critical success index $(C)$ and error bias $(E)$, for the 10and 10,000-year return period flood-prone areas in the Rhône river basin using the RMS flood maps as benchmark.

\begin{tabular}{|l|l|l|l|l|}
\hline Model run & $T P R$ & $F D R$ & $C$ & $E$ \\
\hline Stepwise regression 10-year return period & 0.8749 & 0.6534 & 0.3270 & 161 \\
\hline Stepwise regression 10,000-year return period & 0.8205 & 0.4026 & 0.5052 & 37 \\
\hline Random forest 10-year return period & 0.8618 & 0.6129 & 0.3597 & 159 \\
\hline Random forest 10,000-year return period & 0.8047 & 0.3701 & 0.5268 & 36 \\
\hline
\end{tabular}

Furthermore, cases with a high number of upstream elementary catchments were found to have limited impact on the average results (for more details see supporting information Figure S7 where the performance results for individual elementary catchments of the Rhône river basin are plotted against the corresponding number of upstream elementary catchments). However, there appears to be a higher dispersion of $T P R$, and a tendency for high $F D R$ values for the 10-year return period, with an increasing number of upstream elementary catchments (see supporting information Figure S6 for more details).

\section{Discussion and Future Research}

The work presented in this paper documents the use of two data-driven, expeditious and cost-effective approaches to predict the extents of the envelope of major floods in diverse river basins, gauged or ungauged, and for diverse return periods. This has been achieved by establishing functional relationships in the form of linear and non-linear regression models between specific isolines of a flood descriptor $(\mathrm{TH})$ and geomorphic and climatic-hydrologic characteristics of elementary catchments. This advancement extends a previous approach employed in Tavares da Costa et al. (2019a), by relaxing its complete dependence on benchmark flood maps and by providing a physical basis for the transferability of the TH between catchments, also giving a physical basis to the extrapolation and downscaling goals described in Tavares da Costa et al. (2019a). The results obtained in this work are promising 
for such a novel approach and give an optimistic view about future directions that could improve or extend it. At the same time, the limitations found, and discussed below, should encourage further investigation as new developments can be beneficial to flood managers and insurers giving them nearly instantaneous views of the areas that can potentially be affected by floods.

The classification stage of the methodological workflow showed that, overall and in spite of some outliers, the GFI has an high overall discerning capability of flood-prone areas, as shown by the average $A U C$ value above $91 \%$ for any of the return periods. At the same time, average value of $r_{\phi}$ above $60 \%$ for any of the return periods indicates a strong positive degree of association between the GFI delineated flood-prone areas and the benchmark flood maps. These values are significantly higher than the ones reported by Tavares da Costa et al. (2019a).

The development of estimators of envelope flood extents has shown that in the stepwise regression the VIF and AIC selection of catchment characteristics has been valuable in obtaining statistically significant explanatory variables that improved the explained variance $\left(R^{2}\right)$ of the target and the fit of the initial model (RMSE).

In comparison to the stepwise regression, the random forest regression proved to be a much more flexible and straightforward approach to setup. The final optimized random forest model could be obtained without any prior selection of catchment characteristics and still substantially increase the $R^{2}$ and decrease the RMSE. Moreover, the improvement of the statistical tests by the random forest model seems to provide some evidence of non-linear behaviour between $T H$ and catchment characteristics.

Efforts towards further improving the $R^{2}$ and the RMSE could be undertaken in future work, but only with caution, since the method is not able to represent the dynamics of flooding during specific events and, therefore, cannot entirely replicate results from hydrodynamic models or flooded areas detected using satellite imagery. However, if this was to be pursued, it could be perhaps achieved by adding new or replacing existing single and composite catchment characteristics, which may be specific to each elementary catchment response, and by testing different data transformations in order to increase the correlation with $T H$. It should also be noted that the improvement of some of these quantities may demand more data, raise additional issues and make replicability more difficult without any guarantee of significant performance enhancement in terms of metrics based on the contingency matrix.

When it comes to the predictions of envelope flood extents in the elementary catchments of the Rhône river basin, the random forest regression model performed marginally better than the stepwise regression for any of the return periods considered. Both the stepwise and the random forest regression outputted high $T P R$ values, while at the same time moderate to high $F D R$ values. This was reflected in a moderate to high critical success index, $C$, and in the $E$ values always above 1, indicative of overprediction, especially at lower return periods. As this paper tries to deal with envelope flood extents, overprediction was already expected. Overall, predicted flood-prone areas better match the benchmarks at higher return periods and, particularly for the 10,000-year return period, it is interesting to note that the average performance obtained is in line with some modelling results reported by Wing et al. (2017).

Limitations to this methodological approach are known. For instance, the GFI itself, as detailed by Manfreda et al. (2014, 2015), Samela et al. (2017) and Tavares da Costa et al. $(2019 \mathrm{a}, \mathrm{b})$, is found to be less than optimal in identifying flood-prone areas in flat terrain, 
which may explain the high $F D R$ and overestimation. In other words, in a more incised fluvial valley there are more independent GFI contours to choose from, which allows for a better representation of flood-prone areas. Whereas, in flat or convex terrain (e.g., alluvial fans) fail to constrain flood extents in terms of elevation differences, which means that a small variation of $T H$ can translate into overpredicted flood extents.

Being aware of the limitations of the methodology, there are possibilities to improve flood descriptors. This could be done by: 1) further improving the spatial resolution, vertical accuracy and the processing of the DEM (e.g., de-noising, smoothing and hydrological conditioning, including stream burning); 2) calibrating the coefficient of the power law that scales bankfull depth with contributing area (also in terms of DEM spatial resolution, return period and Strahler stream order); 3) using a multi-directional flow model (e.g., D-Infinity, Tarboton, 1997); and, 4) testing other channel initiation methods (e.g., Li et al., 2020). At the same time upgrading the threshold binary classification and understanding why some elementary catchments are not producing higher $r_{\phi}$ values, will likely help. A number of additional findings are also worth noting:

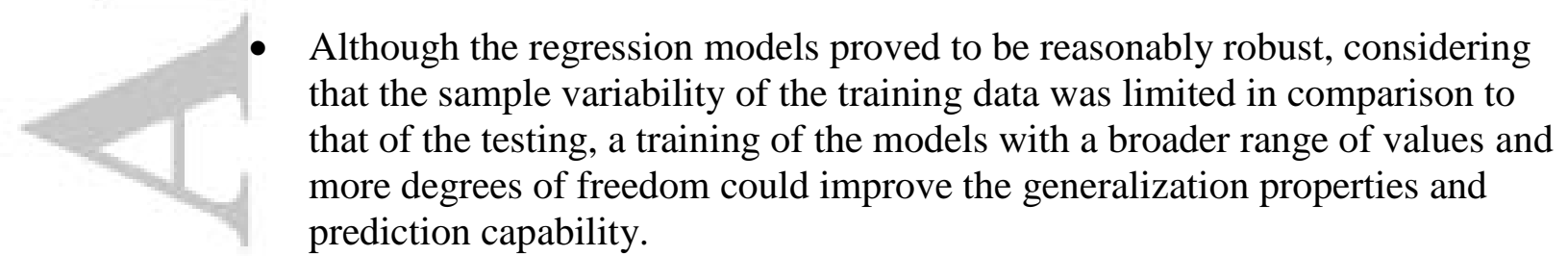

- The random forest regression is not able to predict target values outside the range found in the training dataset and this can be particularly problematic for lower $T H$ values. To account for this feature, different algorithms would need to be considered or modifications to the random forest would need to be implemented.

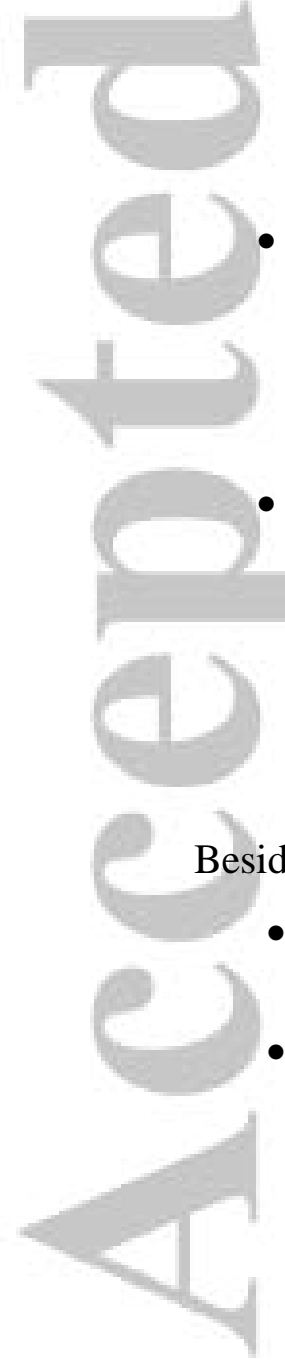

- Explicitly including the case where flooding does not occur in the models (e.g., accurate representation of the river at bankfull flow and the corresponding physical climatic-hydrologic characteristics that lead to it) may benefit the analysis. However, such cases should be completely withheld from the performance analysis, as they might artificially influence the performance.

- Additional tests using the EEA EU-DEM, not reported here, have revealed that the use of a DEM to compute the GFI that is different from the DEM used in the modelling of the benchmark flood maps negatively influences the results. Caution should, thus, be exercised in the selection of the DEM, as in this study (a consistent use of the RMS-DEM), but also in its processing (e.g., terrain analysis, river network and catchment delineation; Tavares da Costa et al., 2019b).

Besides what was mentioned above, future work could:

- Investigate how such methodology performs in other test river basins and whether it could actually be generalized to the global scale.

- Investigate how such methodology would work with benchmark flood extents obtained from remote sensing detection (e.g., Westerhoff et al., 2013; Schumann \& Moller, 2015). It should be noted, however, that observed flood extents will largely reflect the dynamics of the flow, whilst the simplified approach presented here does not. On the other hand, observed flood extents will be dependent on the orbital pass and on the imaging time-windows, it is 


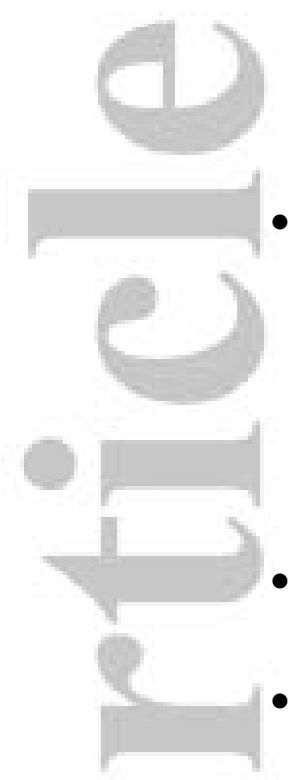

thus important to consider multiple images of the same flood event in order to ensure that the maximum flood extent is best captured (Bernhofen et al., 2018).

- Include more return periods in the analysis, particularly the 100 -year return period flood; as it is considered the standard for risk assessment in many places (e.g., by the US National Flood Insurance Program). At the same time, investigate if bias in performance assessment could be reduced by excluding lower return period from higher return period flood-prone areas (e.g., exclude from the 10,000-year flood prone areas the raster cells corresponding to the 10-year return period flood prone areas).

- Include a broader range of durations for the precipitation statistics, besides the 10 consecutive days precipitation.

- Take a step further and provide a way to estimate flood depth, even if coarsely (e.g., Manfreda \& Samela, 2019).

\section{Acknowledgments}

This project has received funding from the European Union's EU Framework Programme for Research and Innovation Horizon 2020 under Grant Agreement No. 676027.

Data used in this study has been uploaded to an open and free-to-use repository along with scripts (http://dx.doi.org/10.17632/7r8pp8c5ct.1). Some datasets, on which parts of the results are based, cannot be made available, as that would violate the commercial licenses of the products. Licensing information can be found in the company website (https://www.rms.com/).

The authors would like to thank the European Union's Horizon 2020 research and innovation program under the Marie Skłodowska-Curie System-Risk ETN (https://www.system-risk.eu/) grant, David Tarboton (Utah State University) for TauDEM utilities, Leo Breiman and Adele Cutler (Utah State University) for the Random Forest code, the Python Software Foundation for the Python programming language, the Open Source Geospatial Foundation for the Geospatial Data Abstraction Library and the R Foundation for Statistical Computing for the R language and environment. The authors also acknowledge the E-OBS dataset from the EU-FP6 project UERRA (http://www.uerra.eu/) and the Copernicus Climate Change Service, and the data providers in the ECA\&D project (https://www.ecad.eu/). The authors would also like to thank Risk Management Solutions Ltd. for sharing their data, for hosting the corresponding author and for the thoughtful technical discussions held with their flood modelling team. Finally, a word of appreciation to the editors and reviewers of this manuscript, their comments and insights proved invaluable.

This publication reflects only the authors' views and the European Union is not liable for any use that may be made of the information contained therein.

\section{References}

Aerts, J. C. J. H., Renssen, H., Ward, P. J., de Moel, H., Odada, E., Bouwer, L. M. \& Goosse, H. (2006). Sensitivity of global river discharges under Holocene and future climate conditions. Geophysical Research Letters, 33. https://doi.org/10.1029/2006GL027493

Akaike, H. (1974). A new look at the statistical model identification. IEEE Transactions on Automatic Control, 19(6), 716-723. https://doi.org/10.1109/TAC.1974.1100705 
Alfieri, L., Bisselink, B., Dottori, F., Naumann, G., de Roo, A., Salamon, P., Wyser, K. \& Feyen, L. (2017). Global projections of river flood risk in a warmer world. Earth's Future, 5, 171-182. https://doi.org/10.1002/2016EF000485

Alfieri, L., Burek, P., Dutra, E., Krzeminski, B., Muraro, D., Thielen, J. \& Pappenberger, F. (2012). GloFAS - global ensemble streamflow forecasting and flood early warning. Hydrology and Earth System Sciences Discussions, 9, 12293-12332. https://doi.org/10.5194/hessd-9-12293-2012

Alfieri, L., Salamon, P., Bianchi, A., Neal, J., Bates, P. \& Feyen, L. (2014). Advances in panEuropean flood hazard mapping. Hydrological Processes, 28(13), 4067-4077. https://doi.org/10.1002/hyp.9947

Arnaud-Fassetta, G. (2013). Dyke breaching and crevasse-splay sedimentary sequences of the Rhône Delta, France, caused by extreme riverflood of December 2003. Geografia Fisica e Dinamica Quaternaria, 7-26. https://doi.org/10.4461/GFDQ.2013.36.1

Barichivich, J., Gloor, E., Peylin, P., Brienen, R. J. W., Schöngart, J., Espinoza, J. C. \& Pattnayak, K. C. (2018). Recent intensification of Amazon flooding extremes driven by strengthened Walker circulation. Science Advances, 4, eaat8785. https://doi.org/10.1126/sciadv.aat8785

Bartholmes, J. C., Thielen, J., Ramos, M. H. \& Gentilini, S. (2009). The European flood alert system EFAS - Part 2: Statistical skill assessment of probabilistic and deterministic operational forecasts. Hydrology and Earth System Sciences, 13. https://doi.org/10.5194/hess-13-141-2009

Bernhofen, M. V., Whyman, C., Trigg, M. A., Sleigh, P. A., Smith, A. M., Sampson, C. C., Yamazaki, D., Ward, P. J., Rudari, R., Pappenberger, F., Dottori, F., Salamon, P. \& Winsemius, H. C. (2018). A first collective validation of global fluvial flood models for major floods in Nigeria and Mozambique. Environmental Research Letters, 13, 104007. https://doi.org/10.1088/1748-9326/aae014

Beven, K. \& Kirkby, M. (1979). A physically based, variable contributing area model of basin hydrology. Hydrological Sciences Bulletin, 24(1), 43-69. https://doi.org/10.1080/02626667909491834

Bhowmik, N. G. (1984). Hydraulic geometry of floodplains. Journal of Hydrology, 68(1), 369-401. https://doi.org/10.1016/0022-1694(84)90221-X

Bierkens, M. F. P. (2015). Global Hydrology 2015: State, Trends, and Directions. Water Resources Research, 51, 4923-4947. https://doi.org/10.1002/2015WR017173

Bradley, A. P. (1997). The use of the area under the ROC curve in the evaluation of machine learning algorithms. Pattern recognition, 30, 1145-1159. https://doi.org/10.1016/S0031-3203(96)00142-2

Breiman, L. (2001). Random forests. Machine Learning, 45, 5-32. https://doi.org/ 10.1023/A:1010933404324

Breiman, L. \& Cutler, A. (2007). Random forests. University of California, Berkeley. https://www.stat.berkeley.edu/ breiman/RandomForests/reg_copyright.htm (accessed May 2019)

Breiman, L., Friedman, J. H., Olshen, R. \& Stone, C. (1983). Classification and regression trees. Wadsworth 
Caprario, J. \& Finotti, A. R. (2019). Socio-technological tool for mapping susceptibility to urban flooding. Journal of Hydrology, 574, 1152-1163. https://doi.org/10.1016/j.jhydrol.2019.05.005

Castellarin, A., Persiano, S., Pugliese, A., Aloe, A., Skøien, J. O. \& Pistocchi, A. (2018). Prediction of streamflow regimes over large geographical areas: interpolated flowduration curves for the Danube region. Hydrological Sciences Journal, 63, 845-861. https://doi.org/10.1080/02626667.2018.1445855

Coltin, B., McMichael, S., Smith, T. \& Fong, T. (2016). Automatic boosted flood mapping from satellite data. International Journal of Remote Sensing, 37, 993-1015. https://doi.org/10.1080/01431161.2016.1145366

Cornes, R. C., van der Schrier, G., van den Besselaar, E. J. M. \& Jones, P. D. (2018). An Ensemble Version of the E-OBS Temperature and Precipitation Data Sets. Journal of Geophysical Research: Atmospheres, 123, 9391-9409. https://doi.org/10.1029/2017JD028200

Cramér, H. (1999). Mathematical Methods of Statistics, volume Princeton Mathematical Series 9. Princeton University Press.

CRED/UNISDR (2016). The Human cost of weather related disasters 1995-2015. Université Catholique de Louvain, Centre for Research of the Epidemiology of Disasters and The United Nations Office for Disaster Risk Reduction, pp. 30. https://www.unisdr.org/2015/docs/climatechange/COP21_WeatherDisastersReport_2 015_FINAL.pdf

Cunge J. A. (1969). On the subject of a flood propagation computation method (Muskingum method), Journal of Hydraulic Research, 7(2), 205-230. https://doi.org/10.1080/00221686909500264

Cutler, D. R., Edwards, T. C., Beard, K. H., Cutler, A., Hess, K. T., Gibson, J. \& Lawler, J. J. (2007). Random forest for classification in ecology. Ecology, 88, 2783-2792. https://doi.org/10.1890/07-0539.1

Degiorgis, M., Gnecco, G., Gorni, S., Roth, G., Sanguineti, M. \& Taramasso, A. C. (2012). Classifiers for the detection of flood-prone areas using remote sensed elevation data. Journal of Hydrology, 470-471, 302-315. https://doi.org/10.1016/j.jhydrol.2012.09.006

de Moel, H., van Alphen J. \& Aerts, J. C. J. H. (2009). Flood maps in Europe - methods, availability and use. Natural Hazards and Earth System Sciences, 9, 289-301. https://doi.org/10.5194/nhess-9-289-2009

Dodov, B. A. \& Foufoula-Georgiou, E. (2006). Floodplain Morphometry Extraction From a High-Resolution Digital Elevation Model: A Simple Algorithm for Regional Analysis Studies. IEEE Geoscience and Remote Sensing Letters, 3, 410-413. https://doi.org/10.1109/LGRS.2006.874161

Dottori, F., Salamon, P., Bianchi, A., Alfieri, L., Hirpa, F. A. \& Feyen, L. (2016). Development and evaluation of a framework for global flood hazard mapping. Advances in Water Resources, 94, 87-102. https://doi.org/10.1016/j.advwatres.2016.05.002

EEA. EU-DEM - European Digital Elevation Model (v1.0). Copernicus Land Monitoring Service, European Environment Agency. https://land.copernicus.eu/imagery-insitu/eu-dem/eu-dem-v1-0-and-derived-products (accessed May 2019) 
EEA. EU-Hydro (public beta version). Copernicus Land Monitoring Service, European Environment Agency. https://land.copernicus.eu/pan-european/satellite-derivedproducts/eu-hydro (accessed May 2019)

EEA (2016). Flood risks and environmental vulnerability: Exploring the synergies between floodplain restoration, water policies and thematic policies. EEA Report No. 1/2016, European Environment Agency, Copenhagen, Denmark, pp. 84.

https://www.eea.europa.eu/publications/flood-risks-and-environmental-vulnerability

CRED. EM-DAT - The Emergency Events Database. Universite Catholique de Louvain, Centre of Research on the Epidemiology of Disasters. https://www.emdat.be (accessed May 2019)

ECA\&D. E-OBS - ensembles daily gridded observational dataset for precipitation, temperature and sea level pressure in Europe (v19.0e). European Climate Assessment \& Dataset. https://www.ecad.eu/download/ensembles/download.php (accessed May 2019)

Fawcett, T. (2006). An introduction to ROC analysis. Pattern Recognition Letters, 27, 861874. https://doi.org/10.1016/j.patrec.2005.10.010

Fekete, B., Vörösmarty, C. \& Grabs, W. (2002). Global composite runoff fields on observed river discharge and simulated water balances / Water System Analysis Group, University of New Hampshire, and Global Runoff Data Centre. Koblenz, Germany: Federal Institute of Hydrology (BfG).

Fenn, T., Clarke, C., Burgess-Gamble, L., Harding, E., Ogunyoye, F., Hick, E., Dawks, S., Morris, J. \& Chatterton, J. (2016). The costs and impacts of the winter 2013/14 floods in England and Wales. E3S Web of Conferences, 7, 05004. https://doi.org/10.1051/e3sconf/20160705004

Fowler, H. J. \& Kilsby, C. G. (2003). A regional frequency analysis of United Kingdom extreme rainfall from 1961 to 2000. International Journal of Climatology, 23, 13131334. https://doi.org/10.1002/joc.943

UNH/GRDC. Global Composite Runoff Fields V1.0. University of New Hampshire and Global Runoff Data Centre. http://www.compositerunoff.sr.unh.edu (accessed May 2019)

Gaál, L., Szolgay, J., Kohnová, S., Parajka, J., Merz, R., Viglione, A. \& Blöschl, G. (2012). Flood timescales: Understanding the interplay of climate and catchment processes through comparative hydrology. Water Resources Research, 48. https://doi.org/10.1029/2011WR011509

Georgakakos A. P., Georgakakos K. P. \& Baltas, E. A. (1990). A state-space model for hydrologic river routing. Water Resources Research, 26(5), 827-838. https://doi.org/10.1029/WR026i005p00827

Giovannettone, J., Copenhaver, T., Burns, M. \& Choquette, S. (2018). A Statistical Approach to Mapping Flood Susceptibility in the Lower Connecticut River Valley Region. Water Resources Research, 54, 7603-7618. https://doi.org/10.1029/2018WR023018

Grimaldi, S., Petroselli, A., Arcangeletti, E. \& Nardi, F. (2013). Flood mapping in ungauged basins using fully continuous hydrologic-hydraulic modeling. Journal of Hydrology, 487, 39-47. https://doi.org/10.1016/j.jhydrol.2013.02.023 
Haddad, K., Rahman, A. \& Stedinger, J. R. (2012). Regional flood frequency analysis using Bayesian generalized least squares: a comparison between quantile and parameter regression techniques. Hydrological Processes, 26, 1008-1021. https://doi.org/10.1002/hyp.8189

Hirpa, F. A., Salamon, P., Beck, H. E., Lorini, V., Alfieri, L., Zsoter, E. \& Dadson, S. J. (2018). Calibration of the Global Flood Awareness System (GloFAS) using daily streamflow data. Journal of Hydrology, 566, 595-606. https://doi.org/10.1016/j.jhydrol.2018.09.052

Hirsch, R. M., Helsel, D. R., Cohn, T. A. \& Gilroy, E. J. (1992). Statistical analysis of hydrological data, in: Maidment, R. (Ed.), Handbook of Hydrology. McGraw-Hill, New York, pp. 17.1-17.55.

Horritt, M. S. \& Bates, P. D. (2002). Evaluation of 1D and 2D numerical models for predicting river flood inundation. Journal of Hydrology, 268, 87-99. https://doi.org/10.1016/S0022-1694(02)00121-X

Horton, R. E. (1932). Drainage-basin characteristics. Transactions, American Geophysical Union, 13(1), 350. https://doi.org/10.1029/tr013i001p00350

Huntingford, C., Marsh, T., Scaife, A. A., Kendon, E. J., Hannaford, J., Kay, A. L., Lockwood, M., Prudhomme, C., Reynard, N. S., Parry, S., Lowe, J. A., Screen, J. A., Ward, H. C., Roberts, M., Stott, P. A., Bell, V. A., Bailey, M., Jenkins, A., Legg, T., Otto, F. E. L., Massey, N., Schaller, N., Slingo, J. \& Allen, M. R. (2014). Potential influences on the United Kingdom's floods of winter 2013/14. Nature Climate Change, 4, 769-777. https://doi.org/10.1038/nclimate2314

Iorgulescu, I. \& Beven, K. J. (2004). Nonparametric direct mapping of rainfall-runoff relationships: An alternative approach to data analysis and modeling? Water Resources Research, 40. https://doi.org/10.1029/2004WR003094

Jafarzadegan, K. \& Merwade, V. (2017). A DEM-based approach for large-scale floodplain mapping in ungauged watersheds. Journal of Hydrology, 550, 650-662. https://doi.org/10.1016/j.jhydrol.2017.04.053

Jafarzadegan, K. \& Merwade, V. (2019). Probabilistic floodplain mapping using HANDbased statistical approach. Geomorphology, 324, 48-61. https://doi.org/10.1016/j.geomorph.2018.09.024

Jafarzadegan, K., Merwade, V. \& Saksena, S. (2018). A geomorphic approach to 100-year floodplain mapping for the Conterminous United States. Journal of Hydrology, 561, 43-58. https://doi.org/10.1016/j.jhydrol.2018.03.061

Kleinen, T. \& Petschel-Held, G. (2007). Integrated assessment of changes in flooding probabilities due to climate change. Climatic Change, 81, 283-312. https://doi.org/10.1007/s10584-006-9159-6

Kron, W., Eichner, J. \& Kundzewicz, Z. W. (2019). Reduction of flood risk in Europe Reflections from a reinsurance perspective. Journal of Hydrology, 576, 197-209. https://doi.org/10.1016/j.jhydrol.2019.06.050

Kubat, M., Holte, R. C. \& Matwin, S. (1998). Machine Learning for the Detection of Oil Spills in Satellite Radar Images. Machine Learning, 30, 195-215. https://doi.org/10.1023/A:1007452223027 
Li, J., Li, T., Zhang, L., Sivakumar, B., Fu, X., Huang, Y., \& Bai, R. (2020). A D8compatible high-efficient channel head recognition method. Environmental Modelling \& Software, 125, 104624. https://doi.org/10.1016/j.envsoft.2020.104624

Lindeman, R. H., Merenda, P. F. \& Gold, R. Z. (1980). Introduction to Bivariate and Multivariate Analysis. Scott, Foresman and Co., Glenview, IL.

Manfreda, S. \& Samela, C. (2019). A digital elevation model based method for a rapid estimation of flood inundation depth. Journal of Flood Risk Management, e12541. https://doi.org/10.1111/jfr3.12541

Manfreda, S., Nardi, F., Samela, C., Grimaldi, S., Taramasso, A. C., Roth, G. \& Sole, A. (2014). Investigation on the use of geomorphic approaches for the delineation of flood prone areas. Journal of Hydrology, 517, 863-876.

https://doi.org/10.1016/j.jhydrol.2014.06.009

Manfreda, S., Samela, C., Gioia, A., Consoli, G. G., Iacobellis, V., Giuzio, L., Cantisani, A. \& Sole, A. (2015). Flood-prone areas assessment using linear binary classifiers based on flood maps obtained from 1D and 2D hydraulic models. Natural Hazards, 79(2), 735-754. https://doi.org/10.1007/s11069-015-1869-5

Manning, R. (1891). On the flow of water in open channels and pipes. Transactions of the Institution of Civil Engineers of Ireland, 20, 161-207.

Manzato, A. (2007). A Note On the Maximum Peirce Skill Score. Weather and Forecasting, 22, 1148-1154. https://doi.org/10.1175/WAF1041.1

Matthews, B.W. (1975). Comparison of the predicted and observed secondary structure of T4 phage lysozyme. Biochimica et Biophysica Acta, 405(2), 442-451. https://doi.org/10.1016/0005-2795(75)90109-9

McGlynn, B. L. \& Seibert, J. (2003). Distributed assessment of contributing area and riparian buffering along stream networks. Water Resources Research, 39, 1082. https://doi.org/10.1029/2002WR001521

Merz, R \& Blöschl, G. (2005). Flood frequency regionalisation - spatial proximity vs. catchment attributes. Journal of Hydrology, 302, 283-306. https://doi.org/10.1016/j.jhydrol.2004.07.018

Milly, P. C. D., Wetherald, R. T., Dunne, K. A. \& Delworth, T. L. (2002). Increasing risk of great floods in a changing climate. Nature, 415, 514-517. https://doi.org/10.1038/415514a

Morrison, R. R., Bray, E., Nardi, F., Annis, A. \& Dong, Q. (2018). Spatial Relationships of Levees and Wetland Systems within Floodplains of the Wabash Basin, USA. Journal of the American Water Resources Association, 54, 934-948. https://doi.org/10.1111/1752-1688.12652

Nardi, F., Annis, A., Di Baldassarre, G., Vivoni, E. R. \& Grimaldi, S. (2019). GFPLAIN250m, a global high-resolution dataset of Earth's floodplains. Scientific Data, 6, 180309. https://doi.org/10.1038/sdata.2018.309

Nardi, F., Biscarini, C., Di Francesco, S., Manciola, P. \& Ubertini, L. (2013). Comparing a large-scale DEM-based floodplain delineation algorithm with standard flood maps: the Tiber River basin case study. Irrigation and Drainage, 62, 11-19. https://doi.org/10.1002/ird.1818 
Nardi, F., Vivoni, E. R. \& Grimaldi, S. (2006). Investigating a floodplain scaling relation using a hydrogeomorphic delineation method. Water Resources Research, 42, W09409. https://doi.org/10.1029/2005WR004155

Neal, J., Schumann, G. \& Bates, P. (2012a). A subgrid channel model for simulating river hydraulics and floodplain inundation over large and data sparse areas. Water Resources Research, 48 (11), W11506. https://doi.org/10.1029/2012WR012514

Neal, J., Villanueva, I., Wright, N., Willis, T., Fewtrell, T. \& Bates, P. (2012b). How much physical complexity is needed to model flood inundation? Hydrological Processes , 26, 2264-2282. https://doi.org/10.1002/hyp.8339

Nobre, A. D., Cuartas, L. A., Momo, M. R., Severo, D. L., Pinheiro, A. \& Nobre, C. A. (2016). HAND contour: a new proxy predictor of inundation extent. Hydrological Processes, 30(2), 320-333. https://doi.org/10.1002/hyp.10581

Noh, S. J., Lee, J.-H., Lee, S., Kawaike, K. \& Seo, D.-J. (2018). Hyper-resolution 1D-2D urban flood modelling using LiDAR data and hybrid parallelization. Environmental Modelling \& Software, 103, 131-145. https://doi.org/10.1016/j.envsoft.2018.02.008

Pappenberger, F., Dutra, E., Wetterhall, F. \& Cloke, H. L. (2012). Deriving global flood hazard maps of fluvial floods through a physical model cascade. Hydrology and Earth System Sciences, 16, 4143-4156. https://doi.org/10.5194/hess-16-4143-2012

Pappenberger, F., Iorgulescu, I. \& Beven, K. J. (2006). Sensitivity analysis based on regional splits and regression trees (SARS-RT). Environmental Modelling \& Software, 21, 976-990. https://doi.org/10.1016/j.envsoft.2005.04.010

Pearson, K. (1900). On the criterion that a given system of deviations from the probable in the case of a correlated system of variables is such that it can be reasonably supposed to have arisen from random sampling, The London, Edinburgh, and Dublin Philosophical Magazine and Journal of Science, 50, 302, 157-175. https://doi.org/10.1080/14786440009463897

Peirce, C. S. (1884). The numerical measure of success. Science, ns-4, 453-454. https://doi.org/10.1126/science.ns-4.93.453-a

Prieto, C., Le Vine, N., Kavetski, D., García, E. \& Medina, R. (2019). Flow Prediction in Ungauged Catchments Using Probabilistic Random Forests Regionalization and New Statistical Adequacy Tests. Water Resources Research, 55, 5, 4364-4392. https://doi.org/10.1029/2018WR023254

Rebolho, C., Andréassian, V. \& Le Moine, N. (2018). Inundation mapping based on reachscale effective geometry. Hydrology and Earth System Sciences Discussions, 1-18. https://doi.org/10.5194/hess-2018-146

Rennó, C. D., Nobre, A. D., Cuartas, L. A., Soares, J. V., Hodnett, M. G., Tomasella, J. \& Waterloo, M. J. (2008). HAND, a new terrain descriptor using SRTM-DEM: Mapping terra-firme rainforest environments in Amazonia. Remote Sensing of Environment, 112(9), 3469-3481. https://doi.org/10.1016/j.rse.2008.03.018

Samela, C., Manfreda, S., De Paola, F., Giugni, M., Sole, A. \& Fiorentino, M. (2016). DEMbased approaches for the delineation of flood-prone areas in an ungauged basin in Africa. Journal of Hydrologic Engineering, 21(2), 06015010. https://doi.org/10.1061/(ASCE)HE.1943-5584.0001272 
Samela, C., Troy, T. J. \& Manfreda, S. (2017). Geomorphic classifiers for flood-prone areas delineation for data-scarce environments. Advances in Water Resources, 102, 13-28. https://doi.org/10.1016/j.advwatres.2017.01.007

Sampson, C. C., Smith, A. M., Bates, P. B., Neal, J. C., Alfieri, L. \& Freer, J. E. (2015). A high-resolution global flood hazard model. Water Resources Research, 51, 73587381. https://doi.org/10.1002/2015WR016954

Sassi, M., Nicotina, L., Pall, P., Stone, D., Hilberts, A., Wehner, M. \& Jewson, S. (2019). Impact of climate change on European winter and summer flood losses. Advances in Water Resources, S0309170818309977. https://doi.org/10.1016/j.advwatres.2019.05.014

Schröter, K., Kunz, M., Elmer, F., Mühr, B. \& Merz, B. (2015). What made the June 2013 flood in Germany an exceptional event? A hydro-meteorological evaluation. Hydrology and Earth System Sciences, 19, 309-327. https://doi.org/10.5194/hess-19$\underline{309-2015}$

Schumann, G. J.-P., Andreadis, K. M., Bates, P. D. (2014a). Downscaling coarse grid hydrodynamic model simulations over large domains. Journal of Hydrology, 508, 289-298. https://doi.org/10.1016/j.jhydrol.2013.08.051

Schumann, G. J.-P. \& Moller, D. K. (2015). Microwave remote sensing of flood inundation. Physics and Chemistry of the Earth, Parts A/B/C, 83-84, 84-95. https://doi.org/10.1016/j.pce.2015.05.002

Schumann, G. J.-P., Vernieuwe, H., De Baets, B. \& Verhoest, N. E. C. (2014b). ROC-based calibration of flood inundation models. Hydrological Processes, 28, 5495-5502. https://doi.org/10.1002/hyp.10019

Seibert, M., Merz, B. \& Apel, H. (2017). Seasonal forecasting of hydrological drought in the Limpopo Basin: a comparison of statistical methods. Hydrology and Earth System Sciences, 21, 1611-1629. https://doi.org/10.5194/hess-21-1611-2017

Shortridge, J. E., Guikema, S. D. \& Zaitchik, B. F. (2016). Machine learning methods for empirical streamflow simulation: a comparison of model accuracy, interpretability, and uncertainty in seasonal watersheds. Hydrology and Earth System Sciences, 20, 2611-2628. https://doi.org/10.5194/hess-20-2611-2016

Snelder, T. H., Datry, T., Lamouroux, N., Larned, S. T., Sauquet, E., Pella, H. \& Catalogne, C. (2013). Regionalization of patterns of flow intermittence from gauging station records. Hydrology and Earth System Sciences, 17, 2685-2699. https://doi.org/10.5194/hess-17-2685-2013

Tang, Z., Zhang, H., Yi, S. \& Xiao, Y. (2018). Assessment of flood susceptible areas using spatially explicit, probabilistic multi-criteria decision analysis. Journal of Hydrology, 558, 144-158. https://doi.org/10.1016/j.jhydrol.2018.01.033

Tarboton, D.G. (1997). A new method for the determination of flow directions and upslope areas in grid digital elevation models. Water Resources Research, 33, 309-319. https://doi.org/10.1029/96WR03137

Tarboton, D. (2015). TauDEM - Terrain Analysis Using Digital Elevation Models (Version 5). Hydrology Research Group, Utah State University. http://hydrology.usu.edu/taudem/taudem5/ (accessed May 2019) 
Tavares da Costa, R., Manfreda, S., Luzzi, V., Samela, C., Mazzoli, P., Castellarin, A. \& Bagli, S. (2019a). A web application for hydrogeomorphic flood hazard mapping. Environmental Modelling \& Software, 118, 172-186. https://doi.org/10.1016/j.envsoft.2019.04.010

Tavares da Costa, R., Mazzoli, P. \& Bagli, S. (2019b). Limitations Posed by Free DEMs in Watershed Studies: The Case of River Tanaro in Italy. Frontiers in Earth Science, 7, 141. https://doi.org/10.3389/feart.2019.00141

Verdin, K. \& Verdin, J. (1999). A topological system for delineation and codification of the Earth's river basins. Journal of Hydrology, 218, 1-12. https://doi.org/10.1016/S0022$\underline{1694(99) 00011-6}$

Wang, Z., Lai, C., Chen, X., Yang, B., Zhao, S. \& Bai, X. (2015). Flood hazard risk assessment model based on random forest. Journal of Hydrology, 527, 1130-1141. https://doi.org/10.1016/j.jhydrol.2015.06.008

Westerhoff, R. S., Kleuskens, M. P. H., Winsemius, H. C., Huizinga, H. J., Brakenridge, G. R. \& Bishop, C. (2013). Automated global water mapping based on wide-swath orbital synthetic-aperture radar. Hydrology and Earth System Sciences, 17, 651-663. https://doi.org/10.5194/hess-17-651-2013

Wing, O. E. J., Bates, P. D., Sampson, C. C., Smith, A. M., Johnson, K. A. \& Erickson, T. A. (2017). Validation of a $30 \mathrm{~m}$ resolution flood hazard model of the conterminous United States. Water Resources Research, 53, 7968-7986. https://doi.org/10.1002/2017WR020917

Winsemius, H. C., Van Beek, L. P. H., Jongman, B., Ward, P. J. \& Bouwman, A. (2013). A framework for global river flood risk assessments. Hydrology and Earth System Sciences, 17, 1871-1892. https://doi.org/10.5194/hess-17-1871-2013

Wood, M., Hostache, R., Neal, J., Wagener, T., Giustarini, L., Chini, M., Corato, G., Matgen, P.

\& Bates, P. (2016). Calibration of channel depth and friction parameters in the LISFLOOD-FP hydraulic model using medium-resolution SAR data and identifiability techniques. Hydrology and Earth System Sciences, 20, 4983-4997. https://doi.org/10.5194/hess-20-4983-2016

Yamazaki, D., Kanae, S., Kim, H. \& Oki, T. (2011). A physically based description of floodplain inundation dynamics in a global river routing model. Water Resources Research, 47, W04501. https://doi.org/10.1029/2010WR009726

Zanardo, S., Nicotina, L., Hilberts, A. G. J. \& Jewson, S. P. (2019). Modulation of economic losses from European floods by the North Atlantic Oscillation. Geophysical Research Letters, 46, 2563-2572. https://doi.org/10.1029/2019GL081956

Zhao, G., Pang, B., Xu, Z., Peng, D. \& Xu, L. (2019). Assessment of urban flood susceptibility using semi-supervised machine learning model. Science of The Total Environment, 659, 940-949. https://doi.org/10.1016/j.scitotenv.2018.12.217

Zheng, X., Tarboton, D. G., Maidment, D. R., Liu, Y. Y. \& Passalacqua, P. (2018). River Channel Geometry and Rating Curve Estimation Using Height above the Nearest Drainage. JAWRA Journal of the American Water Resources Association, 54, 785806. https://doi.org/10.1111/1752-1688.12661 